\title{
Scoping a field experiment: error diagnostics of TRMM precipitation radar estimates in complex terrain as a basis for IPHEx2014
}

\author{
Y. Duan, A. M. Wilson, and A. P. Barros \\ Department of Civil and Environmental Engineering, Pratt School of Engineering, Duke University, Durham, NC 27708, USA
}

Correspondence to: A. P. Barros (barros@duke.edu)

Received: 9 August 2014 - Published in Hydrol. Earth Syst. Sci. Discuss.: 10 October 2014

Revised: 15 February 2015 - Accepted: 4 March 2015 - Published: 25 March 2015

\begin{abstract}
A diagnostic analysis of the space-time structure of error in quantitative precipitation estimates (QPEs) from the precipitation radar (PR) on the Tropical Rainfall Measurement Mission (TRMM) satellite is presented here in preparation for the Integrated Precipitation and Hydrology Experiment (IPHEx) in 2014. IPHEx is the first NASA ground-validation field campaign after the launch of the Global Precipitation Measurement (GPM) satellite. In anticipation of GPM, a science-grade high-density raingauge network was deployed at mid to high elevations in the southern Appalachian Mountains, USA, since 2007. This network allows for direct comparison between ground-based measurements from raingauges and satellite-based QPE (specifically, PR 2A25 Version 7 using 5 years of data 2008-2013). Case studies were conducted to characterize the vertical profiles of reflectivity and rain rate retrievals associated with large discrepancies with respect to ground measurements. The spatial and temporal distribution of detection errors (false alarm, FA; missed detection, MD) and magnitude errors (underestimation, UND; overestimation, OVR) for stratiform and convective precipitation are examined in detail toward elucidating the physical basis of retrieval error.

The diagnostic error analysis reveals that detection errors are linked to persistent stratiform light rainfall in the southern Appalachians, which explains the high occurrence of FAs throughout the year, as well as the diurnal MD maximum at midday in the cold season (fall and winter) and especially in the inner region. Although UND dominates the error budget, underestimation of heavy rainfall conditions accounts for less than $20 \%$ of the total, consistent with regional hydrometeorology. The 2A25 V7 product underestimates lowlevel orographic enhancement of rainfall associated with fog,
\end{abstract}

cap clouds and cloud to cloud feeder-seeder interactions over ridges, and overestimates light rainfall in the valleys by large amounts, though this behavior is strongly conditioned by the coarse spatial resolution $(5 \mathrm{~km})$ of the topography mask used to remove ground-clutter effects. Precipitation associated with small-scale systems $\left(<25 \mathrm{~km}^{2}\right)$ and isolated deep convection tends to be underestimated, which we attribute to non-uniform beam-filling effects due to spatial averaging of reflectivity at the PR resolution. Mixed precipitation events (i.e., cold fronts and snow showers) fall into OVR or FA categories, but these are also the types of events for which observations from standard ground-based raingauge networks are more likely subject to measurement uncertainty, that is raingauge underestimation errors due to undercatch and precipitation phase.

Overall, the space-time structure of the errors shows strong links among precipitation, envelope orography, landform (ridge-valley contrasts), and a local hydrometeorological regime that is strongly modulated by the diurnal cycle, pointing to three major error causes that are inter-related: (1) representation of concurrent vertically and horizontally varying microphysics; (2) non-uniform beam filling (NUBF) effects and ambiguity in the detection of bright band position; and (3) spatial resolution and ground-clutter correction.

\section{Introduction}

Reliable quantitative measurement of rainfall distribution over mountainous regions is essential for climate studies, hydrological and hazard forecasting, and the management 
of water and ecosystem resources (Barros, 2013; Viviroli et al., 2011). Recent advances toward high spatial and temporal resolution satellite-based quantitative precipitation estimation (QPE) make these estimates potentially attractive for flood forecasting and other operational hydrology studies (e.g., Tao and Barros, 2013, 2014, and references therein). Numerous studies have been conducted to compare satellite products against ground measurements to quantify errors and to improve retrieval algorithms (Amitai et al., 2009, 2012; Barros et al., 2000; Kirstetter et al., 2013; Tao and Barros, 2010; Wolff and Fisher, 2008). For long-term monitoring, raingauges remain the most autonomous and affordable instruments, but large errors can be introduced in extrapolating point observations to represent areal means (Prasetia et al., 2012). Considering the large uncertainties due to satellite temporal sampling and volume sampling discrepancies, and the challenges in accounting for atmospheric heterogeneity and landform complexity, direct comparison of satellitebased precipitation estimates with ground-based point measurements (e.g., raingauges) poses many challenges, especially at short timescales over small areas $(<1000 \mathrm{~km}$; Amitai et al., 2012; Barros and Tao, 2008; Fisher, 2004; among many others).

In mountainous regions, terrain complexity is a key complicating factor not only because it introduces spatial variability, but also because land in this region is difficult to access. This tends to constrain the type, density and locations of ground-based observations, leading to sparse, poorly maintained, and irregularly distributed observing networks. Furthermore, observations from operational ground-based radar systems cannot be relied upon to monitor the lower troposphere due to blockage and ground-clutter effects and, thus, satellite-based observations provide an opportunity for long-term monitoring at high spatial resolution with consistent measurement quality. Studies evaluating satellite QPE consistently report widespread underestimation of rainfall in mountainous regions independently of the temporal scale (Barros et al., 2000; Barros and Tao, 2008; Lang and Barros, 2002; Prat and Barros, 2010a). In the southern Appalachians and the adjacent piedmont, light rainfall $\left(\leq 3 \mathrm{~mm} \mathrm{~h}^{-1}\right)$ accounts for $30-50 \%$ or more of the annual freshwater input to headwater catchments (Barros, 2013; Wilson and Barros, 2014) and, therefore, light rainfall detection and estimation, which has been a long-standing challenge in remote sensing of rainfall, is critical to water cycle studies. On the other hand, vertical complexity and high spatial variability of heavy rainfall and mixed precipitation events associated with severe weather pose major challenges to operational weather and hydrological forecasting of extreme events.

A diagnostic analysis of the space-time structure of error in QPE from the precipitation radar (PR) on the Tropical Rainfall Measurement Mission (TRMM) satellite in preparation for the Integrated Precipitation and Hydrology Experiment (IPHEx) in 2014 is reported here. In particular, we examine the physical basis of false alarm (FA), missed detection (MD), underestimation (UND) and overestimation (OVR) errors with the purpose of designing and implementing a ground-validation observing system that captures the range of key conditions and hydrometeorological regimes linked to various types of retrieval errors and, thus, can inform improvements in retrieval algorithms and precipitation product development in regions of complex orography.

IPHEx is the first ground-validation field campaign after the launch of the Global Precipitation Measurement (GPM) satellite (Barros et al., 2014). The configuration of the terrain and TRMM overpasses and the complex regional meteorology necessitate a comprehensive assessment of the spatial and temporal structure of uncertainty conditional on observing geometry and hydrometeorological regime. In anticipation of IPHEx, a science-grade high-density raingauge network was deployed at mid to high elevations in the southern Appalachian Mountains, USA, since 2007. This network allows for direct comparison of ground-based measurements from raingauges and satellite-based QPE from the TRMM precipitation radar (specifically, PR 2A25 V7), and the GPM Dual-Frequency Precipitation Radar (DPR) when these become available. Specifically, raingauge measurements were compared against 5 years of TRMM orbital precipitation estimates (PR 2A25) collected between 2008 and 2013. The satellite-based estimates were evaluated via gauge-to-pixel analysis for spatiotemporally matched gauges and areal average analysis at the PR pixel scale. Case studies were conducted to characterize the vertical profiles of reflectivity and rain rate associated with large uncertainty, as well as the spatial distribution for typical cases of quantitative errors (UND and OVR) and detection errors (FA and MD) for stratiform and convective precipitation.

Kirstetter et al. (2013) performed a comprehensive study and reported improvements of TRMM PR 2A25 V7 over version 6 (V6) across the southern conterminous US (CONUS) using the National Weather Service (NWS) operational radars and raingauges as reference. Several changes were implemented in the TRMM PR algorithm of V7 including the vertical profile of hydrometeor characteristics, which affects the reflectivity-to-rainfall rate $(Z-R)$ relationship and attenuation correction, and the reintroduction of a correction for non-uniform beam-filling (NUBF) effects (described in Kozu and Iguchi, 1999) that had been removed from V6. Because there are large gaps in the NWS operational observing system in mountainous regions, we build on earlier work by Prat and Barros (2010a) and overlapping V6 and V7 products (TRMM PR 2A25) are also compared here for the 3 years of concurrent availability in the study region (2008-2011).

Section 2 briefly describes the TRMM PR products and the climatology of rainfall observed from the raingauge network, and includes a comparison of TRMM 2A25 V7 and V6 estimates with respect to reference ground measurements focusing on rainfall detectability and quantitative accuracy. Section 3 is devoted to an examination of the vertical reflectivity structures of UND, OVR, FA and MD errors for stratiform 
Table 1. Inventory of long-term raingauges in the Pigeon River basin including the Great Smoky Mountains National Park (GSMNP) in the southern Appalachians used in this study.

\begin{tabular}{lllll}
\hline Raingauge & Latitude & Longitude & Elevation $(\mathrm{m})$ & Series \\
\hline RG001 & 35.4 & -82.91 & 1156 & \\
RG002 & 35.43 & -82.97 & 1731 & \\
RG003 & 35.38 & -82.92 & 1609 & RG0XX eastern ridge \\
RG004 & 35.37 & -82.99 & 1922 & \\
RG005 & 35.41 & -82.96 & 1520 & \\
RG008 & 35.38 & -82.97 & 1737 & \\
RG010 & 35.46 & -82.95 & 1478 & \\
\hline RG100 & 35.59 & -83.07 & 1495 & \\
RG101 & 35.58 & -83.09 & 1520 & \\
RG102 & 35.56 & -83.1 & 1635 & \\
RG103 & 35.55 & -83.12 & 1688 & \\
RG104 & 35.55 & -83.09 & 1587 & \\
RG105 & 35.63 & -83.04 & 1345 & \\
RG106 & 35.43 & -83.03 & 1210 & \\
RG107 & 35.57 & -82.91 & 1359 & \\
RG108 & 35.55 & -82.99 & 1277 & \\
RG109 & 35.5 & -83.04 & 1500 & \\
RG110 & 35.55 & -83.15 & 1563 & \\
RG111 & 35.73 & -82.95 & 1394 & \\
RG112 & 35.75 & -82.96 & 1184 & \\
\hline RG300 & 35.73 & -83.22 & 1558 & \\
RG301 & 35.71 & -83.26 & 2003 & \\
RG302 & 35.72 & -83.25 & 1860 & \\
RG303 & 35.76 & -83.16 & 1490 & \\
RG304 & 35.67 & -83.18 & 1820 & \\
RG305 & 35.69 & -83.13 & 1630 & \\
RG306 & 35.75 & -83.17 & 1536 & \\
RG307 & 35.65 & -83.2 & 1624 & \\
RG308 & 35.73 & -83.18 & 1471 & \\
RG309 & 35.68 & -83.15 & 1604 & \\
RG310 & 35.7 & -83.12 & 1756 & \\
RG311 & 35.77 & -83.14 & 1036 & \\
\hline & & & & \\
\end{tabular}

and convective rainfall as defined by TRMM-based criteria with the purpose of characterizing the uncertainty in each class and exploring the physical basis of associated errors. Section 4 focuses on diagnosing the potential sources of errors for illustrative case studies. Summary and conclusions follow in Sect. 5.

\section{Data}

\subsection{The GSMNP raingauge network}

A high spatial resolution raingauge network has been installed in the Great Smoky Mountains National Park (GSMNP) in the southern Appalachians since 2007 (Prat and Barros, 2010b). In this study, 32 stations equipped with tipping bucket (TB) gauges operating for the longest continuous period, distributed at mid to high elevations (from
1150 to $1920 \mathrm{~m}$ ) on mountain ridges, will be used as reference "ground-truth" (Table 1, Fig. 1). The current network configuration includes additional raingauges, disdrometers, MicroRain Radars (MRRs) and weighing raingauges (Barros et al., 2014), but in this study we use only the TB raingauge data that have several years of record length during the 2008-2013 period, thus assuring robust statistics. The raingauges provide point observations of surface rainfall at different measurement resolution: seven raingauges use the TB3 model (RG0XX: catchment size of $200 \mathrm{~mm}$; $0.2 \mathrm{~mm} \mathrm{tip}^{-1}$ ), 13 are TB3/0.1 (RG1XX: catchment size of $282.2 \mathrm{~mm} ; 0.1 \mathrm{~mm} \mathrm{tip}^{-1}$ ) and 12 are HS305 (RG3XX: catchment size of $\left.305 \mathrm{~mm} ; 1 \mathrm{~mm} \mathrm{tip}^{-1}\right)$. Note the RG3XX data are available only from 2009 onward. Although higherresolution TB gauges were co-located with several RG3XX gauges since their initial deployment, their record is short and thus those observations are not used here. To reiterate, a note of caution is warranted with regard to the many poten- 


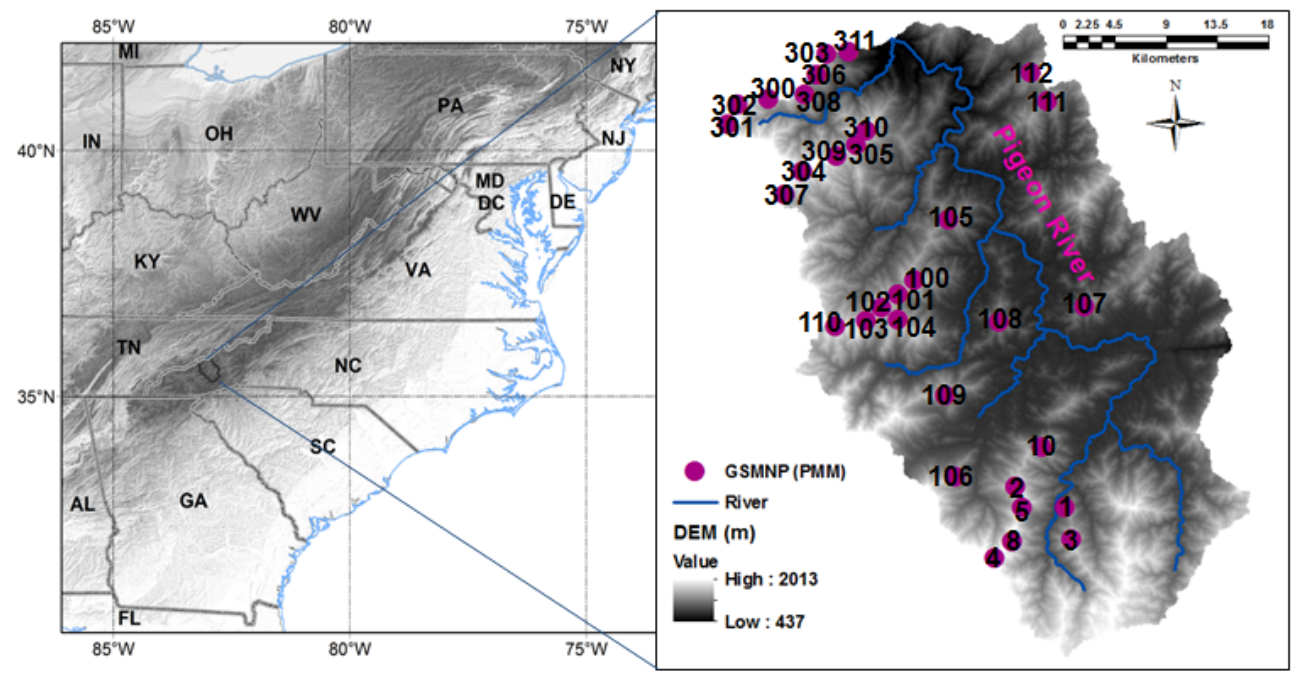

Figure 1. Region of study including the GSMNP in the southern Appalachians. The right panel shows the Pigeon River basin where the raingauges are installed. Note RG0XX, RG1XX, and RG3XX were installed in summer 2007, 2008, and 2009, respectively. Additional raingauges and other instrumentation placed in the region are not shown here (see http://iphex.pratt.duke.edu).

tial errors due to spatial density and geolocation distribution of the gauges, wind effects, surface wetting of the gauge funnel, animal and human interference, evaporation, and splashing that may introduce error in the raingauge observations independently of the measurement accuracy proper. For example, for high wind speeds, the reported rain rate is typically $2-18 \%$ lower than the actual value (Chen et al., 2013; Wang and Wolff, 2010). Nevertheless, the raingauge measurements provide a reliable and independent reference to evaluate uncertainties and identify possible biases associated with remote-sensing estimates.

Over the southern Appalachians, most precipitation is associated with stratiform systems, although isolated thunderstorms and mesoscale convective systems are dominant in the warm season. Figure 1 shows a map of the study region, where the GSMNP network is a relatively dense raingauge network deployed in the Pigeon River basin in the southern Appalachians spanning an area of about $1400 \mathrm{~km}^{2}$. As can be seen in Fig. 1, the RG0XX (easternmost) and RG3XX (westernmost) gauges are clustered over the outer ridges, whereas the RG1XX gauges are distributed in the inner mountain region. Figure 2 shows the spatial variability of average daily precipitation raingauge accumulations over the period of study. Note the lack of classic orographic rainfall enhancement with elevation (Fig. 2b), as well as the stronger variability for the RG1XX gauges in the inner mountain region (blue colors) with higher rainfall totals at lower elevations in the valleys and at ridge tops and a decrease at intermediate elevations on hill slopes. The high values in the valleys reflect the contribution of seeder-feeder processes resulting from the interaction of stratiform rainfall with low-level clouds and thick fog banks (Wilson and Barros, 2014). Complex orographic precipitation effects in
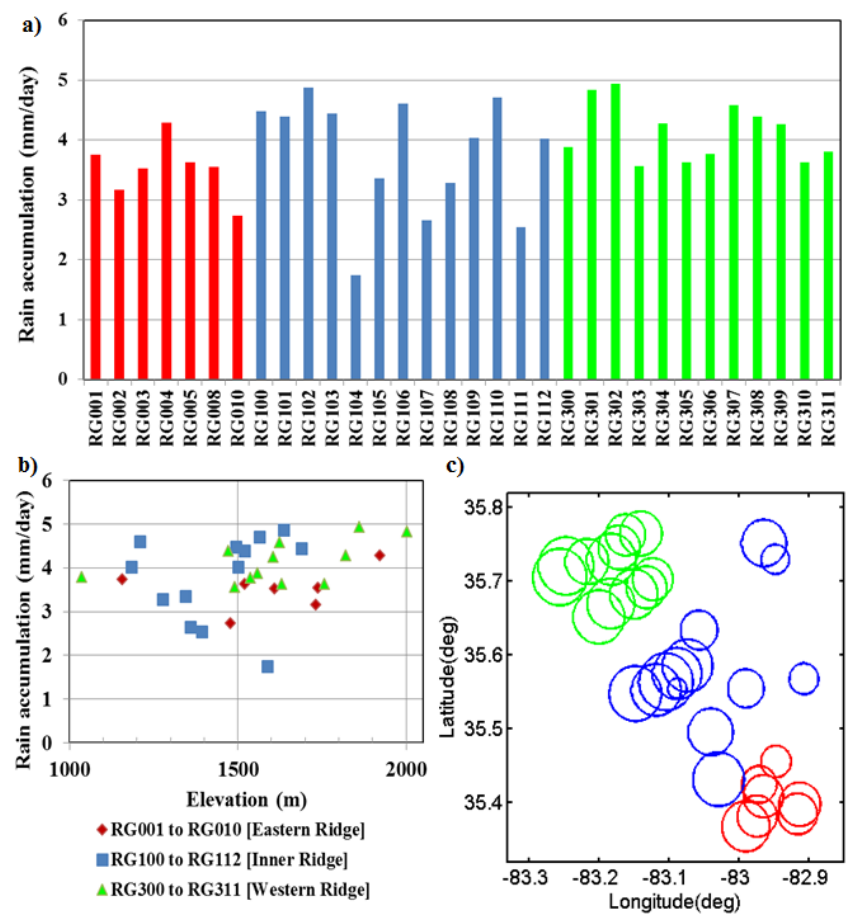

Figure 2. (a) Average rain accumulation $\left(\mathrm{mm} \mathrm{day}^{-1}\right)$ for the raingauges deployed in the GSMRGN. Average rain accumulation as a function of (b) elevation and (c) geolocation of each raingauge with circle size indicating relative magnitude of the daily rain accumulation.

the southern Appalachian Mountains and high intra-annual variability in large-scale weather conditions explain the high spatial variability in the diurnal cycle of rainfall frequency from one season to another as depicted in Fig. 3. During 

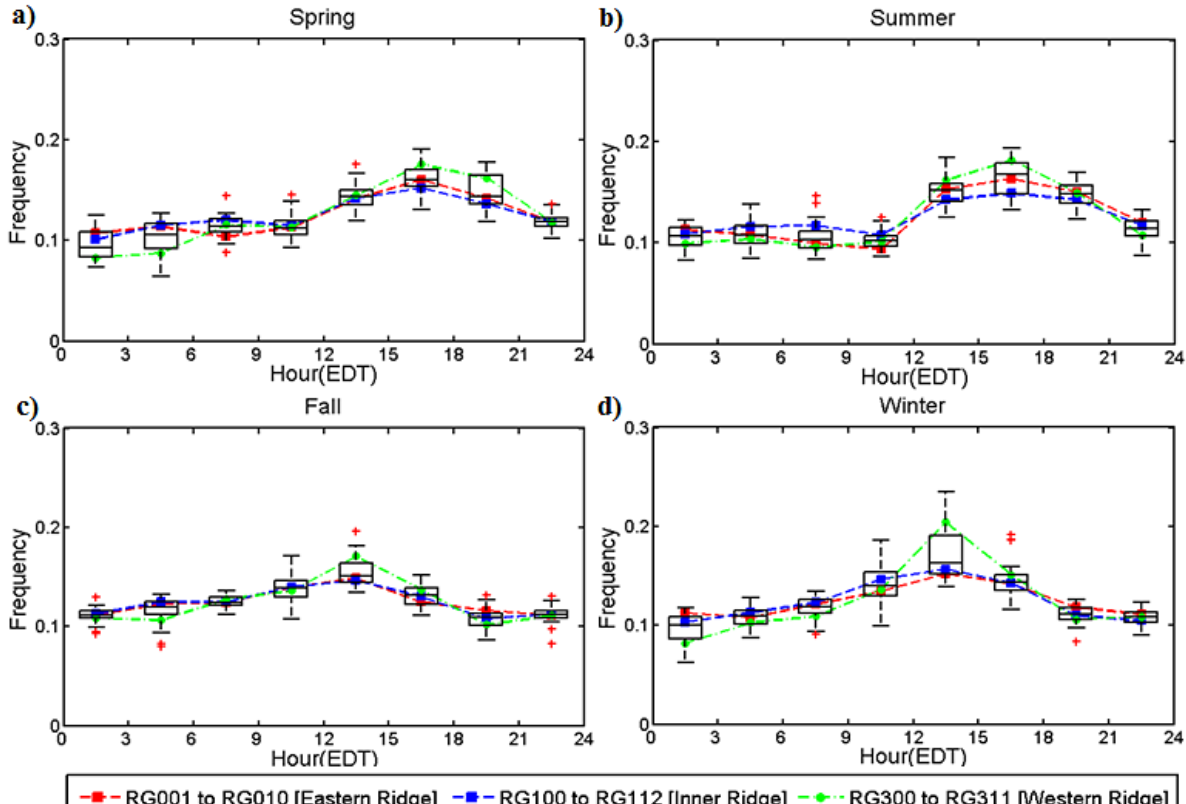

- RG001 to RG010 [Eastern Ridge] - RG100 to RG112 [Inner Ridge] - - RG300 to RG311 [Western Ridge]

Figure 3. Three-hourly diurnal cycle as a function of the season of the year and the raingauge network location (eastern, inner, and western ridges) for (a) spring (April-May-June), (b) summer (July-August-September), (c) fall (October-November-December), (d) winter (JanuaryFebruary-March).

the summer, rainfall frequency peaks in the late afternoon (15:00 to 18:00 EDT - eastern daylight time) with daytime convection accounting for nearly $20 \%$ of the seasonal total and is somewhat uniform in the remainder of the day with each period contributing about $10-15 \%$; during the winter, rainfall frequency reveals a strong diurnal cycle characterized by a high-amplitude maximum in the early afternoon (12:00 to 15:00 EDT) and a relative minimum occurring between 21:00 and 06:00 EDT. Spring and fall seasons, on the other hand, exhibit a much weaker diurnal cycle, with a relative maximum occurring in the afternoon and otherwise more or less constant throughout the rest of the day.

\subsection{TRMM PR 2A25 products}

The TRMM satellite was launched in November 1997 and operated on a non-sun-synchronous orbit designed to capture precipitation structure in the tropics. On 8 July 2014 NASA ceased station keeping maneuvers and TRMM is currently drifting downward from its operating altitude of 402 to $335 \mathrm{~km}$, an altitude expected to be reached around February 2016, at which point data collection will be terminated. The PR is the first active microwave instrument used for measuring three-dimensional rainfall structures over the tropics and subtropics from space (Kozu et al., 2001) and produces more reliable near-surface estimates of precipitation at a higher spatial resolution than radiometers including in mountainous regions (Barros et al., 2000; Barros and Tao, 2008; Nesbitt et al., 2000). The PR operates at $13.8 \mathrm{GHz}$ frequency with $250 \mathrm{~m}$ vertical resolution and is thus capable of penetrating dense cloud layers to detect underlying precipitation (Prasetia et al., 2012). Retrieval errors such as the uncertainty of the assumed drop size distribution (DSD), incorrect physical assumptions (freezing-level height, hydrometeor temperatures), possible contamination by surface backscatter, the reliability and physical basis of the stratiform-convective classification, attenuation and extinction of the signal and NUBF effects, light rain sensitivity (minimum detectable signal), and surface clutter rejection all contribute to uncertainty in PR rainfall estimates, and the respective effects are corrected to varying degrees (Iguchi et al., 2009; Wolff and Fisher, 2008).

Specifically, a hybrid of the surface reference technique and the Hitschfeld and Bordan method is applied to correct for atmospheric attenuation (Iguchi et al., 2000). The PR attenuation correction is adequate in stratiform rain but is underestimated in convective rain, particularly for heavy rain accumulations (Liao and Meneghini, 2009). Generally, application of the attenuation correction can change the estimated rain rate by an order of magnitude in cases of heavy precipitation (Bindlish and Barros, 2000; Iguchi et al., 2000; Meneghini et al., 2000). Generally, the NUBF effects refer to underestimation errors in the presence of reflectivity gradients, that is, subgrid-scale volume heterogeneity at the relatively coarse resolution of the PR footprint (Durden et al., 1998; Nakamura, 1991). Previous studies evaluating the impact of NUBF have been conducted for ocean conditions and for moderate to heavy rainfall conditions, and 
results suggested very small errors due to NUBF for the TRMM PR; however, no studies focused on subgrid-scale effects in mountainous regions where there is a strong coorganization of landform and precipitation along with strong space-time variability. Other sources of errors include the orbital geometry of the satellite at relatively high latitudes (Fisher, 2004), and local hydrometeorological regimes which may present cloud and rainfall vertical structure very different from that implied in the retrieval algorithm's microphysical assumptions. Intercomparison of precipitation estimates from different algorithms allows for examination of the specific impacts of algorithm differences on QPE reliability and accuracy. For instance, the underestimation of rain rate in V6 (Prat and Barros, 2010a) was addressed in the $\mathrm{V} 7$ algorithm revisions by recalibration of the $Z-R$ relationship over land and implementation of the NUBF correction to produce larger estimates both over land and over ocean (Seto et al., 2011). Finally, sampling errors are subject to sampling frequency and the spatiotemporal structure of precipitation associated with diurnal, seasonal, and inter-annual variability of rainfall within a region. Even though sampling errors are more randomly distributed, they can be a significant contribution to the total error (Fisher, 2004). The main TRMM product used in this work is the PR $2 \mathrm{~A} 25 \mathrm{~V} 7$ product, described at http://disc.sci.gsfc.nasa.gov/precipitation/ documentation/TRMM_README. V6 products are used for assessing V7 algorithm improvements, specifically with regard to instantaneous precipitation estimates. For this purpose, all rainfall measurements observed coincidentally by TRMM overpasses and the GSMNP network from June 2008 to May 2011 are used.

An important challenge in the validation of satellitederived estimations against ground measurements is the resolution discrepancy of different data sets. Here, all the raingauge measurements within a $2.5 \mathrm{~km}$ radius from the center of the PR pixel position for each PR overpass within a selected timescale are integrated into one. Nevertheless, matching the observations from raingauges and TRMM PR at the nominal pixel scale $(\sim 5 \mathrm{~km})$ in space and time introduces uncertainties due to differences in the measurement control volume, generally referred to as representativeness error (i.e., Porcù et al., 2014), which is further aggravated due to sparse spatial sampling and topographic variations: raingauges report near-surface point rainfall rate while satellite estimates correspond to a cloud volume-averaged rainfall rate, which is also highly dependent on the precipitation system, cloud physics and morphology, and associated rainfall (e.g., Habib and Krajewski, 2002; Prat and Barros, 2010a). However, this discrepancy can be alleviated by using an optimal integration time interval for gauge observations (Prat and Barros, 2009; Wang and Wolff, 2010) as it is done in this manuscript (see Sect. 2.3). Despite these challenges, comparisons with ground reference gauges constitute a critical component in evaluating the accuracy of the PR estimates of surface precipitation, reflectivity and rain rate.

\subsection{Comparison of TRMM PR $2 A 25$ V7 vs. V6}

\subsubsection{Rainfall detection}

As stated earlier, the objective of the revisions implemented in the TRMM PR V7 algorithm was to correct some key deficiencies identified in the V6 algorithm, namely the large underestimation of rain over land relative to ground-based measurements and the relatively large dependence of rain estimates on the viewing angle (Iguchi et al., 2009). A detailed summary of the major changes in the TRMM PR retrieval algorithm are summarized in Iguchi et al. (2009) and Okamoto et al. (2008). Here, V6 and V7 rain rates from June 2008 to May 2011 corresponding to 3 years of satellite overpasses over the southern Appalachians are compared. Note that V6 data are only available up to summer 2011. To evaluate the satellite estimates, rain rate estimates for a given pixel are compared to the observed values at raingauges located within the pixel's fingerprint $(\sim 5 \mathrm{~km}$ diameter). The number of raingauges varies from pixel to pixel but, on average, about two gauges can be found in each PR field of view. To determine whether there is an optimal timescale that reconciles the nearly instantaneous (point in time) satellite-based areal rainfall estimates (pixel scale) with raingauge observations (point in space) with different measurement resolution (TB size), the gauge rain rates are integrated over a range of timescales (10-60 min) centered at the time of overpass and spatially averaged at the PR pixel scale. To evaluate precipitation detectability (contingency tables and statistical skill scores), point-to-pixel comparisons were applied to increase the sample size and avoid ambiguity associated with the spatial representativeness of the gauges within the pixel. When multiple gauges exist in the same pixel, the PR measurements are paired separately with different raingauges. It is assumed that the PR resolution remains constant for both near-nadir and off-nadir inclination angles. To avoid contamination due to the resolution deformation, the PR-RG pairs were segregated into "near-nadir" (scanning inclination angles ranging from 0 to $9^{\circ}$ ) and "off-nadir" (scanning inclination angles beyond $9^{\circ}$ ) comparisons. Off-nadir pairs are discarded in some quantitative comparisons to exclude the angle deformation in exploring other sources of error. In this section, the TRMM PR 2A25 near-surface rain rate was analyzed with respect to the independent ground reference rainfall data to examine the detectability performance of satellite rainfall retrievals using contingency tables and statistical skill scores. The rain detection and surface clutter discrimination are primarily handled by the Level 1 algorithms (e.g., 1B21 and 1C21 products), which have been improved over time (e.g., change of clutter routine module in PR 1B21 from V6 to V7). Level 1 products are used subsequently as input to the Level 2 algorithm. For example, the near-surface rain rate from $2 \mathrm{~A} 25$ is retrieved based on the identification of clutter-free ranges from $1 \mathrm{C} 21$. Therefore, the higher level product $2 \mathrm{~A} 25$ reflects the integra- 
Table 2. Contingency matrices for TRMM 2A25 V7 surface rain rate and 10 min raingauge rain rates for (a) all angles and (b) near-nadir cases. Counts are expressed as a percentage of the total number of observations. Values in parentheses are for V6. The 10 min timescale is centered over the time of the satellite overpass during June 2008-May 2011.

\begin{tabular}{lllll}
\hline (a) & \multicolumn{4}{c}{ All angles (RG0XX and RG1XX) } \\
\hline & & Yes & No & Tot. \\
TRMM PR 2A25 & Yes & $1.18(1.12)$ & $2.73(3)$ & $3.91(4.12)$ \\
& No & $0.74(0.71)$ & $95.35(95.17)$ & $96.09(95.88)$ \\
& Tot. & $1.93(1.83)$ & $98.07(98.17)$ & $100(100)$ \\
\hline \multirow{4}{*}{ (b) } & \multicolumn{4}{c}{ Near-nadir cases (RG0XX and RG1XX) } \\
\hline \multirow{4}{*}{ TRMM PR 2A25 } & Yes & $2.23(2.01)$ & No & Tot. \\
& No & $1.24(1.28)$ & $93.7(93.59)$ & $5.06(5.13)$ \\
& Tot. & $3.47(3.29)$ & $96.53(96.71)$ & $100(100)$ \\
\hline
\end{tabular}

Table 3. Rainfall detection metrics for TRMM 2A25 V7 (V6) compared to RG observations as a function of timescale (10, 20, 30, 60 min) during June 2008-May 2011. Note the definitions of the skill scores are provided below. $Y$ indicates positive detection; $N$ indicates no detection.

\begin{tabular}{|c|c|c|c|c|c|c|c|c|c|c|c|c|c|}
\hline & \multicolumn{12}{|c|}{ Time window (min) } & \multirow{3}{*}{$\begin{array}{l}\text { Perfect } \\
\text { Score }\end{array}$} \\
\hline & \multicolumn{3}{|c|}{$10 \mathrm{~min}$} & \multicolumn{3}{|c|}{$20 \mathrm{~min}$} & \multicolumn{3}{|c|}{$30 \mathrm{~min}$} & \multicolumn{3}{|c|}{$60 \mathrm{~min}$} & \\
\hline & All & $0 \mathrm{XX}$ & $1 \mathrm{XX}$ & All & $0 X X$ & $1 \mathrm{XX}$ & All & $0 \mathrm{XX}$ & $1 \mathrm{XX}$ & All & $0 \mathrm{XX}$ & $1 \mathrm{XX}$ & \\
\hline Accuracy $^{\mathrm{a}}$ & $\begin{array}{l}0.97 \\
(0.96)\end{array}$ & $\begin{array}{l}0.96 \\
(0.96)\end{array}$ & $\begin{array}{l}0.97 \\
(0.97)\end{array}$ & $\begin{array}{l}0.96 \\
(0.96)\end{array}$ & $\begin{array}{l}0.96 \\
(0.96)\end{array}$ & $\begin{array}{l}0.97 \\
(0.96)\end{array}$ & $\begin{array}{l}0.96 \\
(0.96)\end{array}$ & $\begin{array}{l}0.96 \\
(0.96)\end{array}$ & $\begin{array}{l}0.96 \\
(0.96)\end{array}$ & $\begin{array}{l}0.95 \\
(0.94)\end{array}$ & $\begin{array}{l}0.94 \\
(0.94)\end{array}$ & $\begin{array}{l}0.95 \\
(0.95)\end{array}$ & 1 \\
\hline $\mathrm{FB}^{\mathrm{b}}$ & $\begin{array}{l}1.5 \\
(1.65)\end{array}$ & $\begin{array}{l}1.7 \\
(1.84)\end{array}$ & $\begin{array}{l}1.39 \\
(1.55)\end{array}$ & $\begin{array}{l}1.02 \\
(1.12)\end{array}$ & $\begin{array}{l}1.05 \\
(1.12)\end{array}$ & $\begin{array}{l}1.01 \\
(1.12)\end{array}$ & $\begin{array}{l}0.83 \\
(0.89)\end{array}$ & $\begin{array}{l}0.83 \\
(0.87)\end{array}$ & $\begin{array}{l}0.82 \\
(0.91)\end{array}$ & $\begin{array}{l}0.59 \\
(0.63)\end{array}$ & $\begin{array}{l}0.56 \\
(0.59)\end{array}$ & $\begin{array}{l}0.6 \\
(0.66)\end{array}$ & 1 \\
\hline $\mathrm{POD}^{\mathrm{c}}$ & $\begin{array}{l}0.61 \\
(0.61) \\
\end{array}$ & $\begin{array}{l}0.6 \\
(0.58) \\
\end{array}$ & $\begin{array}{l}0.61 \\
(0.62) \\
\end{array}$ & $\begin{array}{l}0.55 \\
(0.55) \\
\end{array}$ & $\begin{array}{l}0.55 \\
(0.54) \\
\end{array}$ & $\begin{array}{l}0.55 \\
(0.56) \\
\end{array}$ & $\begin{array}{l}0.49 \\
(0.49) \\
\end{array}$ & $\begin{array}{l}0.51 \\
(0.5) \\
\end{array}$ & $\begin{array}{l}0.48 \\
(0.49) \\
\end{array}$ & $\begin{array}{l}0.4 \\
(0.4) \\
\end{array}$ & $\begin{array}{l}0.42 \\
(0.4) \\
\end{array}$ & $\begin{array}{l}0.39 \\
(0.4) \\
\end{array}$ & 1 \\
\hline FAR $^{\mathrm{d}}$ & $\begin{array}{l}0.59 \\
(0.63)\end{array}$ & $\begin{array}{l}0.65 \\
(0.68)\end{array}$ & $\begin{array}{l}0.56 \\
(0.6)\end{array}$ & $\begin{array}{l}0.46 \\
(0.51)\end{array}$ & $\begin{array}{l}0.47 \\
(0.52)\end{array}$ & $\begin{array}{l}0.45 \\
(0.5)\end{array}$ & $\begin{array}{l}0.41 \\
(0.45)\end{array}$ & $\begin{array}{l}0.39 \\
(0.43)\end{array}$ & $\begin{array}{l}0.42 \\
(0.46)\end{array}$ & $\begin{array}{l}0.32 \\
(0.36)\end{array}$ & $\begin{array}{l}0.26 \\
(0.31)\end{array}$ & $\begin{array}{l}0.36 \\
(0.39)\end{array}$ & 0 \\
\hline $\mathrm{POFD}^{\mathrm{e}}$ & $\begin{array}{l}0.02 \\
(0.03)\end{array}$ & $\begin{array}{l}0.03 \\
(0.03)\end{array}$ & $\begin{array}{l}0.02 \\
(0.03)\end{array}$ & $\begin{array}{l}0.02 \\
(0.02)\end{array}$ & $\begin{array}{l}0.02 \\
(0.02)\end{array}$ & $\begin{array}{l}0.02 \\
(0.02)\end{array}$ & $\begin{array}{l}0.02 \\
(0.02)\end{array}$ & $\begin{array}{l}0.02 \\
(0.02)\end{array}$ & $\begin{array}{l}0.02 \\
(0.02)\end{array}$ & $\begin{array}{l}0.01 \\
(0.02)\end{array}$ & $\begin{array}{l}0.01 \\
(0.01)\end{array}$ & $\begin{array}{l}0.01 \\
(0.02)\end{array}$ & 0 \\
\hline $\mathrm{TS}^{\mathrm{f}}$ & $\begin{array}{l}0.32 \\
(0.3)\end{array}$ & $\begin{array}{l}0.28 \\
(0.26)\end{array}$ & $\begin{array}{l}0.35 \\
(0.32)\end{array}$ & $\begin{array}{l}0.37 \\
(0.35)\end{array}$ & $\begin{array}{l}0.37 \\
(0.34)\end{array}$ & $\begin{array}{l}0.38 \\
(0.36)\end{array}$ & $\begin{array}{l}0.37 \\
(0.35)\end{array}$ & $\begin{array}{l}0.38 \\
(0.36)\end{array}$ & $\begin{array}{l}0.36 \\
(0.34)\end{array}$ & $\begin{array}{l}0.34 \\
(0.33)\end{array}$ & $\begin{array}{l}0.36 \\
(0.34)\end{array}$ & $\begin{array}{l}0.32 \\
(0.32)\end{array}$ & 1 \\
\hline
\end{tabular}

${ }^{\mathrm{a}}$ Accuracy: $(Y Y+N N) /$ total; ${ }^{\mathrm{b}}$ frequency bias: $\mathrm{FB}=(Y Y+Y N) /(Y Y+N Y) ;{ }^{\mathrm{c}}$ probability of detection: $\mathrm{POD}=Y Y /(Y Y+N Y) ;{ }^{\mathrm{d}}$ false alarm ratio:

$\mathrm{FAR}=Y N /(Y Y+Y N) ;{ }^{\mathrm{e}}$ probability of false detection: $\mathrm{POFD}=Y N /(N N+Y N) ;{ }^{\mathrm{f}}$ threat score: $\mathrm{TS}=Y Y /(Y Y+N Y+Y N)$.

tion of Level 1 results, and can serve as a fair indicator of effective rainfall detectability of TRMM.

The contingency matrices of PR estimates, with regard to the gauge observations at a 10 min timescale for all angles (a) and for near-nadir cases only (b), are presented in Table 2. Table 3 provides a summary of detection metrics (i.e., skill scores) based on the counts of hits $(Y Y)$, misses $(N Y)$, false alarms $(Y N)$ and correct rejections $(N N)$ inferred from contingency matrices at timescales ranging from 10 to 60 min: accuracy, frequency bias (FB), probability of detection (POD), false alarm ratio (FAR), probability of false detection (POFD), and threat score (TS). The equations to calculate the skill scores are included as footnotes to Table 3.
The results for all raingauges (see Table 2a) for V7 show the percentage of correct detections (rain events detected simultaneously by the TRMM PR and raingauges: $\sim 1 \%$ ) is lower than the number of false alarms (events registered by the TRMM and not recorded by raingauge: $\sim 3 \%$ ), but higher than the number of missed detections (events observed by raingauges but missed by TRMM: $\sim 0.7 \%$ ). The agreement in the number of rejections (when both TRMM and raingauges do not detect rain) is expected. Although the specific quantitative values are different, the skill for near-nadir viewing angles (Table $2 b$ ) is nearly the same as that for all cases (Table 2a). Overall, V7 exhibits slightly better detection skill than V6 as indicated by the higher probability of correct de- 
a)

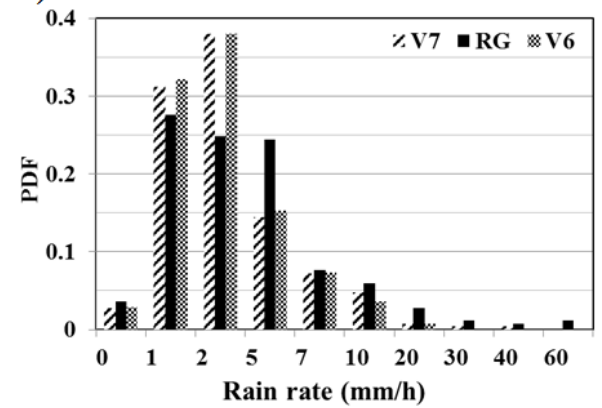

b)

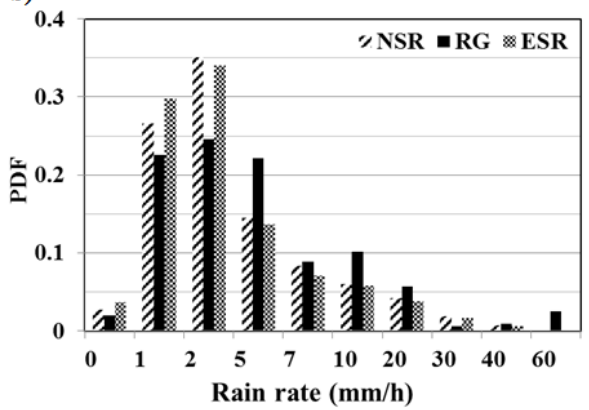

Figure 4. (a) Probability distributions of rain rates for V7 and V6 comparison of non-null TRMM $2 \mathrm{~A} 25$ near-surface rain rate (NSR) estimates and average raingauge rain rates for near-nadir pixels (scanning inclination angles ranging from 0 to $9^{\circ}$ ) during the period 1 June 200831 May 2013; (b) probability distribution of non-null TRMM 2A25 V7 surface rain rate products (estimated surface rain rate (ESR) and NSR) and average gauge rain rates during the period 1 June 2008-31 May 2013. Raingauge rain rates are calculated using timescales of 10 (RG0XX and RG1XX) and 30 min (RG3XX) corresponding to the interval centered at the time of satellite overpasses.

tection and correct rejection, and lower probability of false alarms and missed detection.

Results from the sensitivity study of the skill scores to timescale of integration of raingauge observations centered at the time of TRMM overpasses are summarized in Table 3. TB RG3XX data are excluded from this comparison considering its coarse measurement accuracy $\left(1 \mathrm{~mm} \mathrm{tip}^{-1}\right)$, and due to the fact that the record length of concurrent V6 and V7 is too short. V6 and V7 exhibit similar skill in accuracy and POFD at different timescales. The FB scores, which indicate whether TRMM has a tendency to underestimate $(<1)$ or overestimate $(>1)$ rainfall, show strong sensitivity to the timescale of integration, followed by the gauge measurement sensitivity. Unbiased results are obtained at the 20 min timescale with skill scores close to perfect (1). The POD scores decrease with the timescale as expected due to the space-time intermittency of rainfall, and no significant improvements were found in V7 as compared to V6. FAR scores, which count how often the satellite products detect rainfall in the absence of rainfall at the gauges, are slightly lower for V7. Lower scores are observed in the RG1XX series in the inner mountain region than in the RG0XX series on the eastern ridges, possibly because of the raingauge measurement threshold (RG0XX: $0.2 \mathrm{~mm} \mathrm{tip}^{-1}$, RG1XX: $0.1 \mathrm{~mm} \mathrm{tip}^{-1}$ ) and location (RG0XX: outer ridge, RG1XX: inner ridge). The TS values, which are sensitive to correct detection and penalize for both missed detections and false alarms, are consistently higher in V7 as compared to V6, but only slightly so. Overall, this analysis indicates that V7 improvements in rainfall detection in the southern Appalachians are minimal relative to V6. This result is consistent with Kirstetter et al. (2013), who reported improvement in QPE but not in detection metrics for $2 \mathrm{~A} 25 \mathrm{~V} 7$ products relative to V6.

\subsubsection{Quantitative precipitation estimation (QPE)}

To assess the accuracy of TRMM PR rainfall estimates, histograms of concurrent satellite near-surface rain rate (NSR) estimates and gauge observations for the near-nadir cases are displayed in Fig. 4a, using the average raingauge rates at the PR pixel scale. Only non-zero data pairs are used, and thereby large amounts of non-rainy days are excluded from this comparison. The overestimation of the relative frequency of light rainfall $\left(<5 \mathrm{~mm} \mathrm{~h}^{-1}\right)$ results from QPE underestimation of heavier rainfall. Figure $4 \mathrm{~b}$ suggests that V7 NSR estimates of moderate rainfall rates are higher than estimated surface rain rate (ESR) estimates. In addition, scatterplots and regression analysis were examined (not shown here) for ESR and NSR against raingauge observations with similar results to those reported by Prat and Barros (2010a). Compared to V6, a smaller slope is obtained in V7 for these two TRMM products, which is consistent with Seto et al. (2011), who showed that V7 rain rate estimates are larger than in V6 over land and over ocean. The tendency to underestimate rain rate (slope >1) has been mitigated in V7 with slopes closer to unity, thus indicating better agreement with the reference ground observations. The severe underestimation of heavy rainfall rates in both versions can be attributed at least in part to the lack of areal representativeness of the raingauges which are point estimates in contrast with the area-averaged $\left(5 \times 5 \mathrm{~km}^{2}\right)$ TRMM rainfall estimates, although the point estimates of rain rate are reduced by using a timescale of at least $10 \mathrm{~min}$ centered at the satellite overpass time.

\section{Statistics and physical basis of PR 2 A25 V7 error structure}

The physical basis of error structure in V7 is assessed focusing on the space-time variability of error and how it relates to storm structure for UND, OVR, FA and MD cases. This sec- 

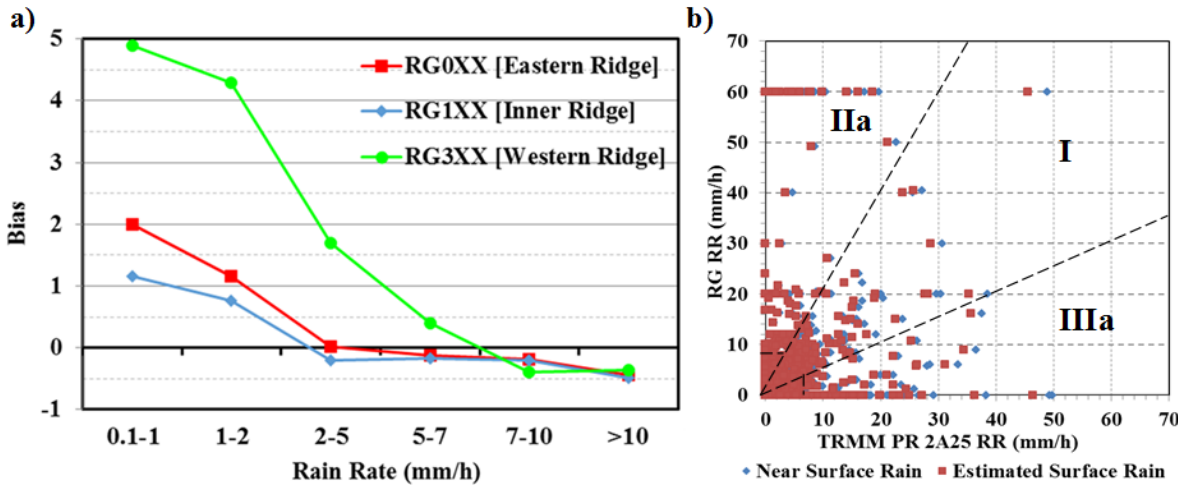

Figure 5. (a) Bias between TRMM 2A25 V7 NSR and average raingauge rain rates for different series: RG0XX, RG1XX, and RG3XX (see Table 1); (b) scatterplot for TRMM 2A25 V7 surface rain rates (NSR and ESR) and average raingauge rain rates during the period 1 June 2008-31 May 2013. Raingauge rain rates are using a 10 min (RG0XX and RG1XX) and 30 min (RG3XX) scale centered at the time of the satellite overpasses. Note the raingauge measurement and TRMM profile classifications as described in Table 4 (five primary categories, I-II-III-IV-V, and two subcategories, IIa-IIIa).

tion is organized by first evaluating the overall quantitative performance of TRMM precipitation estimates compared to gauge data, next, examining the rain type, rain rate, and the temporal distribution over a spectrum of timescales (e.g., diurnal and seasonal) and, finally, exploring the relationship between rainfall error and vertical reflectivity structure.

\subsection{Surface rain rate classes}

The error analysis of TRMM estimates for 1820 PR overpasses in the southern Appalachians during 2008-2013 is presented here. The reference rainfall is computed in a similar manner to that described earlier by selecting raingauges that lie within a $2.5 \mathrm{~km}$ radius around the center of the PR pixel. A sensitivity analysis of bias was conducted on four TRMM PR 2A25 precipitation products: ESR, NSR, 2$4 \mathrm{~km}$ averaged rain rate, and integrated column rain rate at various timescales ranging from 10 to $60 \mathrm{~min}$ (not shown here). Results for TRMM NSR indicate that bias is minimized at 10 min timescales for RG0XX and RG1XX, and 30 min for RG3XX estimates (RG0XX: $\sim 0.5$, RG1XX: $\sim 0.2$, RG3XX: $\sim 0$ ). Consequently, 10 and $30 \mathrm{~min}$ (centered at the time of overpass) rain rates from RG0XX and RG1XX and RG3XX, respectively, will be used as reference hereafter. As seen in Fig. 5a, bias is lowest overall in the inner mountain region (RG1XX). Overestimation of light rainfall leads to large positive bias everywhere, but is much larger on the western ridges (RG3XX) than on the eastern ridges (RG0XX) or in the inner region (RG1XX) consistent with the gauges' measurement resolution (Fig. 5a); for moderate and heavier rain rates $\left(>5 \mathrm{~mm} \mathrm{~h}^{-1}\right)$, the bias is negative, relatively small, and uniformly distributed.

Regression analysis (not shown here) of PR 2A25 V7 rainfall estimates (NSR and ESR) vs. averaged gauge data indicates that for non-null PR-gauge pairs, both estimates derived from PR are in good agreement (regression slope close to one) with the ranges of rainfall intensity associated with the regional hydrometeorological regimes, but the $R^{2}$ value is very low for both estimates (NSR: 0.09, ESR: 0.08), which likely results from significant discrepancies for heavy rainfall events.

In order to better understand the quantitative discrepancy between TRMM and RG, the matched PR pixels and raingauge cluster pairs are classified into five distinct categories corresponding to the relative difference $(\varepsilon)$ of the 2A25 estimates with respect to raingauge observations (see Fig. 5b and Table 4). The same classes are used later in the manuscript to examine TRMM reflectivity profiles. In Table 4, regardless of the value of the discrepancy in the rainfall rate estimates, conditions when rain was simultaneously observed by the satellite and raingauges (cases I, II, III) correspond to approximately $31 \%$ of all cases, while about $50 \%$ report rain for TRMM only (case IV, FA), and about $19 \%$ report rain for raingauges only (case V, MD). As will be shown later in more detail (see Fig. 7a), a large fraction of FAs and MDs occurs at larger viewing angles $\left(>8^{\circ}\right)$ in which case NUBF uncertainty is expected to be higher. However, the predominance of FAs raises concerns about the reliability of the algorithm in mountainous regions. In order to address this question, an evaluation was conducted by comparing concurrent TB and weighing raingauge observations (not shown here). The analysis indicates that the TB raingauges miss detection of light rainfall events of short duration $(<30 \mathrm{~min})$ with accumulations below their measurement sensitivity, corresponding to circumstances when wind and turbulence undercatch effects can be dominant, but these circumstances are not statistically meaningful. Significant discrepancies between TB and weighing raingauges occur for snowfall conditions when near-surface air temperature is below $0{ }^{\circ} \mathrm{C}$, but this is still a small number of events ( $\sim 15 \%$ of FAs) in the region of study. Thus, the problem of excessive spurious detection can- 
Table 4. Classification of TRMM 2A25 reflectivity profiles as a function of the difference ( $\varepsilon$ ) (RR_TRMM2A25 - RR_RG) / RR_RG that represents the relative error of the $2 \mathrm{~A} 25$ estimates with respect to the raingauge observations. The timescale of integration is 10 min for RG0XX and RG1XX and 30 min for RG3XX, which corresponds to the minimum error bias for the period of record. Bold values correspond to $\varepsilon=0.5$.

\begin{tabular}{llll}
\hline \multirow{2}{*}{ Class } & \multicolumn{3}{l}{ Diff $(\varepsilon)=($ RR_TRMM - RR_RG $) /$ RR_RG } \\
\cline { 2 - 4 } & $\varepsilon=0.25$ & $\varepsilon=\mathbf{0 . 5 0}$ & $\varepsilon=0.75$ \\
\hline I : Abs(Diff) $<\varepsilon$ & 126 & $\mathbf{2 3 7}$ & 368 \\
II $:$ Diff $<-\varepsilon$ & 259 & $\mathbf{1 7 4}$ & 70 \\
IIa $:$ Diff $<-\varepsilon$ and RR_RG $>7 \mathrm{~mm} \mathrm{~h}^{-1}$ & 99 & $\mathbf{7 6}$ & 45 \\
III $:$ Diff $>\varepsilon$ & 165 & $\mathbf{1 3 9}$ & 112 \\
IIIa $:$ Diff $>\varepsilon$ and RR_TRMM $>7 \mathrm{~mm} \mathrm{~h}^{-1}$ & 50 & $\mathbf{4 3}$ & 35 \\
\hline IV $:$ RR_RG $=0$ and RR_TRMM $\neq 0$ & 863 & $\mathbf{8 6 3}$ & 863 \\
V $:$ RR_RG $\neq 0$ and RR_TRMM $=0$ & 330 & $\mathbf{3 3 0}$ & 330 \\
\hline Total & 1743 & $\mathbf{1 7 4 3}$ & 1743 \\
\hline
\end{tabular}

not be explained by $\mathrm{TB}$ raingauge measurement limitations alone.

An overview of the organization of error categories as a function of rain type and rain rate is provided in Fig. 6. The rain type (derived in TRMM $2 \mathrm{~A} 23$ as a parameter to separate convective and stratiform rain) and rain rate categories follow the error classification framework described in Table 4. A large fraction of UND errors (class II) is associated with "probably stratiform" (rain type: 120) rainfall by the TRMM PR algorithm in the winter, but over $60 \%$ correspond to heavy rainfall events (see Table 4, IIa) and most convective rainfall (200 and 210) occurs during the summer. There is a relatively small number of samples overall (the UND 5-year total is only 174, see Table 4). The errors tend to cluster at specific times of day that are consistent with the regional hydrometeorology, thus, enhancing our confidence on the diurnal cycle and providing a physical basis for attribution. Indeed, a survey of the results shows that the diurnal cycle of UND error peaks during the period 15:0018:00 EDT (not shown here), a time of day typically associated with daytime solar forcing of convective activity. The histograms of TRMM and raingauge rain rate estimates for UND events (Fig. 6a, right panel) have a different skew with TRMM PR NSR estimates mostly below $5 \mathrm{~mm} \mathrm{~h}^{-1}$, whereas most raingauge observations exceed $10 \mathrm{~mm} \mathrm{~h}^{-1}$. This indicates that UND errors cannot be corrected using linear bulk adjustments such as bias correction; rather, physical insight is needed to improve retrievals.

OVR (class III) errors are mostly associated with wintertime precipitation classified as "probably stratiform". Inspection (not shown here) of the apparent annual and diurnal cycles of OVR errors (note again the limited sample size on an hourly basis: 5 -year total OVR is 139 , Table 4, III) indicates that these errors exhibit a diurnal cycle peaking in January and March during daytime (09:00-15:00 EDT), consistent with the diurnal cycle of rainfall in winter (Fig. 3d). A good overall agreement between the histograms of raingauge and TRMM rain rates (Fig. 6b, right panel) for these events suggests that bias correction of OVR errors should lead to immediate improvements in TRMM PR products. Figure 6c shows that FA (IV) errors are also associated with "stratiform" and "probably stratiform" rainfall throughout the year and light rainfall rates $\left(<5 \mathrm{~mm} \mathrm{~h}^{-1}\right)$.

Overall, the results show that the error budget of TRMM PR NSR estimates is largely controlled by ambiguity in the detection of the bright band (stratiform conditions) for significantly off-nadir observations (significant NUBF effects) for light rainfall conditions in all seasons and generally in the wintertime.

\subsection{Space-time error structure}

A survey of precipitation detectability skill in the TRMM PR 2A25 V7 from the point of view of FA and MD errors is presented in Fig. 7. The impact of the observing geometry is explored in Fig. 7a, focusing specifically on the interplay between complex orography, satellite orbit, and the viewing angle for each pixel in the satellite's swath. Detection skill depends on the orbit and the specific trajectory of the satellite over the region. For the eastern ridges (RG0XX series), a large portion of FA occurs at small angles, in particular $\sim 5^{\circ}$, reflecting the geometry of the overpasses and the terrain underneath as the satellite approaches the Appalachians; in the inner ridges (RG1XX series) more cases are observed around 8 and $11^{\circ}$; for the western ridges (RG3XX series) almost all cases are registered at off-nadir angles $\left(\geq 9^{\circ}\right)$, especially around $11^{\circ}$. Note that at larger viewing angles (RG1XX and RG3XX) the radar signal also travels through a longer trajectory and, thus, an extended liquid water path. Figure $7 \mathrm{~b}$ and c display the diurnal and seasonal distributions of FAs and MDs corresponding to rainfall classes IV and V (Table 3). Note the strong diurnal cycle of FAs peaking at midday and early afternoon, especially in the case of the inner region 

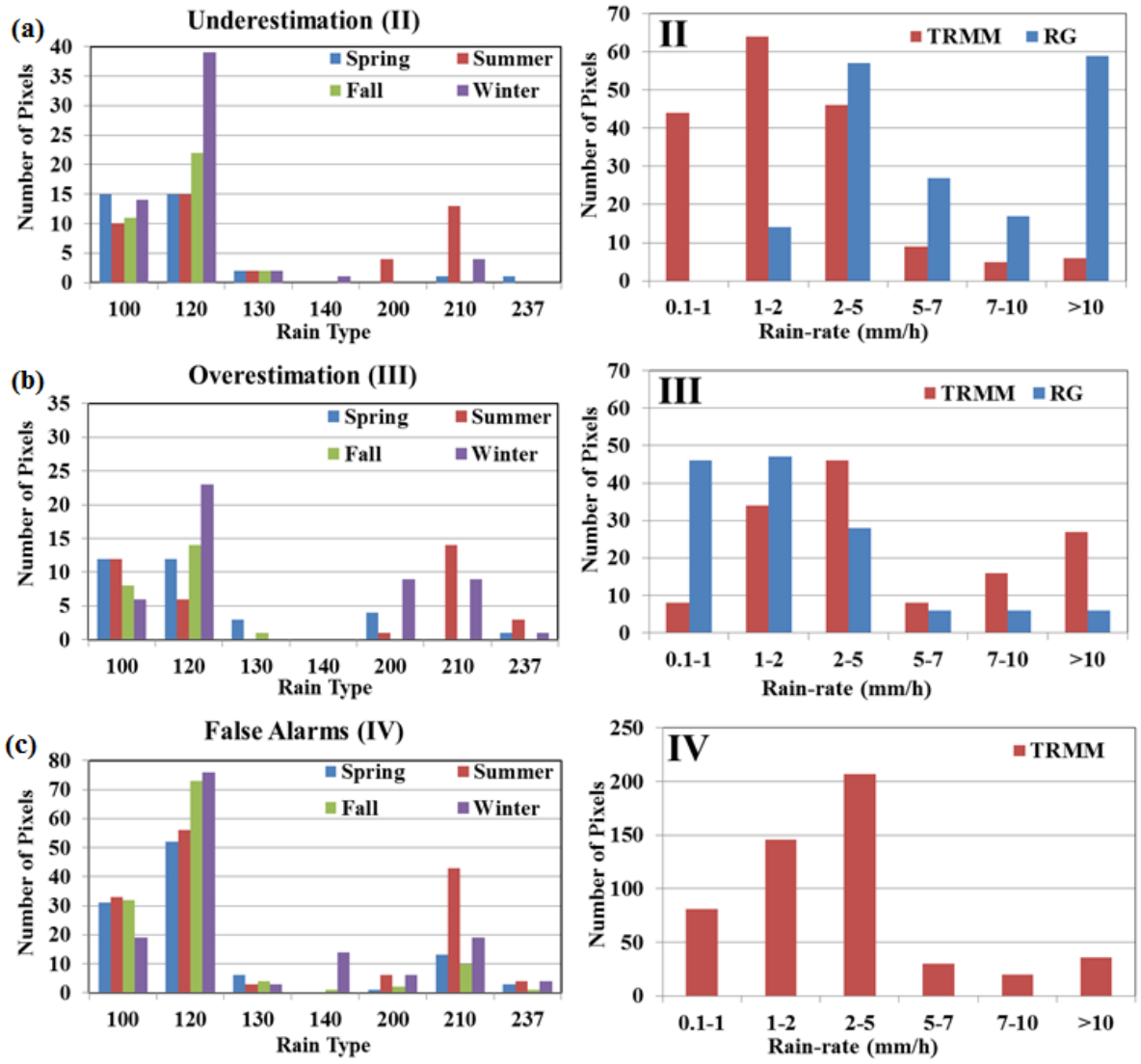

Figure 6. Histogram of rain type (left panels) and observed RG rain rate and NSR from TRMM (right panels) distributions for the different errors: (a) II (UND); (b) III (OVR); and (c) IV (FA). The error classification is provided in Table 4. The rain type categories correspond to the TRMM 2A23 rain-type flag: 100 - stratiform certain, 120 - probably stratiform, 130 - maybe stratiform, 140 - maybe stratiform or maybe transition or something else, 200 and 210 - convective certain, 237 - probably convective. (For further details please see the $2 \mathrm{~A} 23$ documentation at http://disc.sci.gsfc.nasa.gov/precipitation/documentation/TRMM_README).

(blue color). The seasonal cycle shows that FAs in the eastern ridges and western ridges are relatively uniformly distributed throughout the year, whereas they peak in the summer in the inner ridges. Furthermore, the number of FAs and MDs in the inner region is very high and dominates overall statistics. Close examination of the diurnal cycle reveals that most FAs in the summer occur in the afternoon (12:00-18:00 EDT), corresponding to diurnal convective activity, while winter cases follow the diurnal cycle of precipitation pattern peaking in the early afternoon (not shown here).

Among all MD cases, most are classified as "no rain" and some are categorized as "other", whereas only three are classified as stratiform and none are considered convective (not shown here). Figure $7 \mathrm{~b}$ and $\mathrm{c}$ for MDs (class V) show a strong diurnal cycle with most occurring around 12:0015:00 EDT and a seasonal trend with a large proportion occurring during the cold season, which is attributed to the frequent presence of fog and low-level clouds in the fall and winter seasons, especially in the inner region (RG1XX). The very small count of MDs in the western ridges (RG3XX) is explained in part by the coarse gauge sensitivity $\left(1 \mathrm{~mm} \mathrm{tip}^{-1}\right.$,
30 min timescale) and because fog seldom develops over this region due to strong winds. Dense and deep fog formation during the fall and winter seasons in the inner mountain region establishes conditions for enhanced stratiform rainfall via seeder-feeder mechanisms at low levels $(<1 \mathrm{~km})$ that is measured by the gauges in the inner mountain region (e.g., Wilson and Barros, 2014) but cannot be detected by the TRMM PR due to the topography and automatic groundclutter correction. In addition, the minimum detectable signal of TRMM PR is approximately $18 \mathrm{dBZ}\left(0.4 \mathrm{~mm} \mathrm{~h}^{-1}\right)$ (Heymsfield et al., 2000; Yang and Nesbitt, 2014) and, thus, weak radar reflectivity for light rainfall can also partly explain MD statistics.

\subsection{TRMM PR reflectivity profile and rainfall detectability}

Here, we examine the relationship between rainfall detectability and the vertical reflectivity structure of TRMM PR. To facilitate the comparison of various types of precipitation including the distinction between convective and strat- 

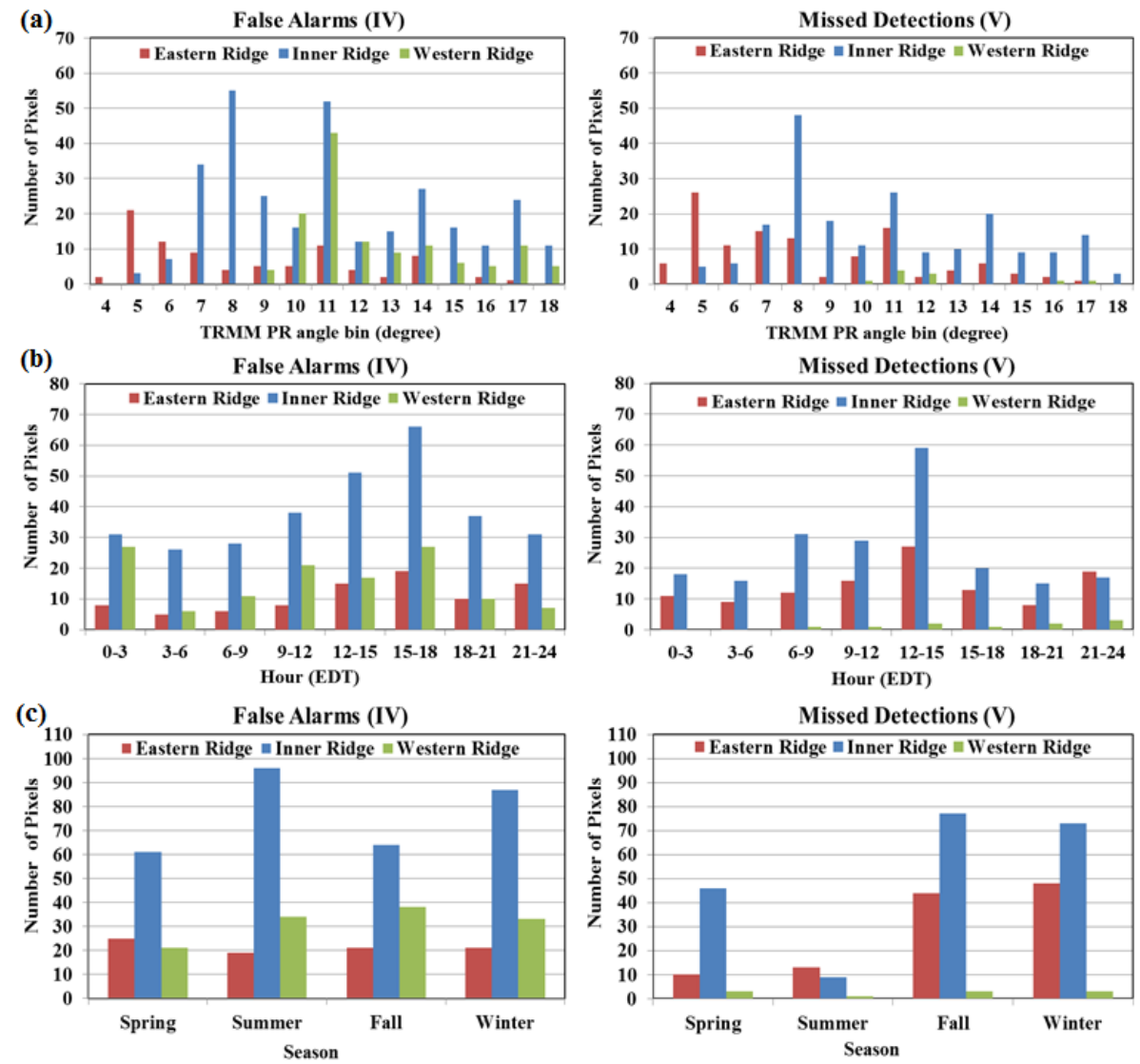

Figure 7. Histograms of FA (left panel) and MD (right panel) occurrences as a function of the viewing angle (a), time of the day (b) and season of the year (c). As previously, the colors correspond to raingauges aligned with the eastern (red, RG0XX), western (green, RG3XX) and inner ridges (blue, RG1XX) in the region of study (Fig. 1, Table 1).

iform precipitation by TRMM-derived criteria, three categories of reflectivity profiles have been identified (see Fig. 8): (1) stratiform with bright band (BB); (2) stratiform without $\mathrm{BB}$; and (3) convective. Note that the reflectivity profile is used in the rain classification algorithm, in addition to the precipitation rate estimation proper.

For stratiform UND cases (see Fig. 8a and b, class II), the reflectivity gradually decreases with altitude and the median values between 2 and $4 \mathrm{~km}$ are in the range of $20-30 \mathrm{dBZ}$ approximately. Some UND cases (see the red outliers in Fig. 8b, II) display high cloud tops (up to $9 \mathrm{~km}$ ), consistent with the heavy rainfall events in Fig. 6a that are indicative of warm rain with embedded convection. Reflectivity data below $2 \mathrm{~km}$ are often removed due to ground-clutter contamination. In Fig. 8a (III), the mean reflectivity profile shows a decreasing tendency with height (from $2.75 \mathrm{~km}$ toward the ground surface), suggesting that summertime OVR errors are likely linked to light rainfall evaporating before it reaches the ground (see rain type: 100 in Fig. 6b). Compared to the UND (II) cases (left panels in Fig. 8), the reflectivity profiles for OVR cases show steeper positive gradients at lower levels, in particular below $3 \mathrm{~km}$, and more measurements are avail- able below $2 \mathrm{~km}$ altitude in the convective cases (see Fig. $8 \mathrm{~b}$ and c, III). The downward decreasing trend of reflectivity toward the surface is also evident in the reflectivity profiles of FAs for stratiform conditions with and without the bright band (see Fig. 8a, IV), which can also be explained by raindrop evaporation during the summer (see rain type: 100 in Fig. 6c). Compared to the UND and OVR cases in Fig. 8a and $b$, the FA stratiform reflectivity profiles decrease more gradually with altitude at lower levels. Note the rapid reflectivity increase (35-50 dBZ) below $2 \mathrm{~km}$ in the convective cases (IV, Fig. 8c). This feature will be further discussed next in the context of error diagnosis and interpretation. Overall, steeper positive gradients in reflectivity are displayed in OVR cases at lower levels, while the decreasing trend with height shown in UND and FA possibly indicates light rainfall evaporation before reaching the ground. The high cloud tops in UND are characteristic of warm stratiform rainfall with embedded convection, resulting in heavy rainfall events. 

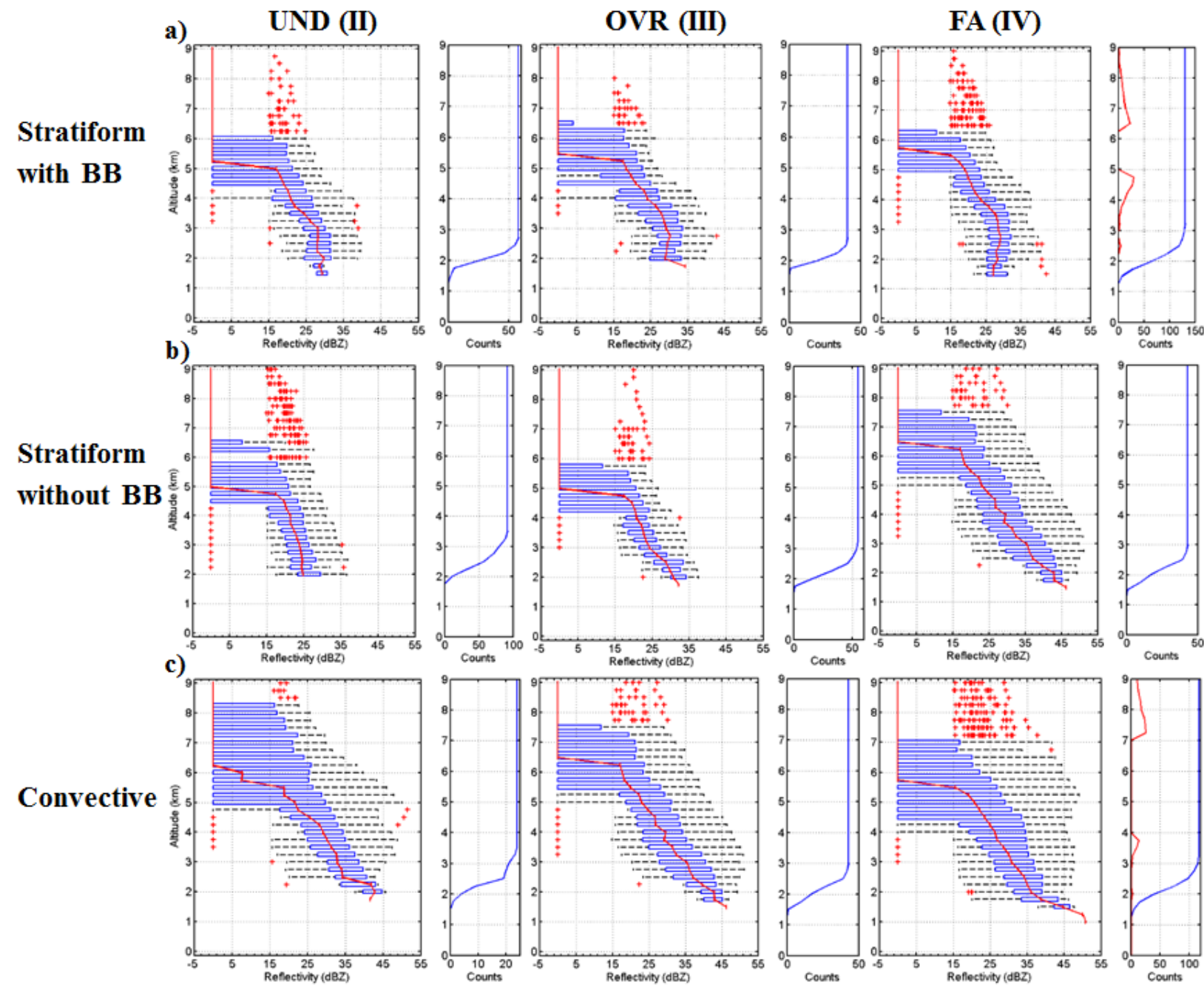

Figure 8. TRMM 2A25 reflectivity profiles for error classes II (UND), III (OVR), and IV (FA): (a) stratiform conditions with BB detected (rain type: 100 and 130, Fig. 6), (b) stratiform conditions without BB detected (rain type: 120 and 140, Fig. 6), and (c) convective conditions (rain type: 200, 210, and 237, Fig. 6). The blue box denotes the interquartile range (IQR) from the lower quartile (25th) to the upper quartile (75th); the median is indicated by the red mark inside the box. The red line connects the median reflectivity at all levels to yield the median reflectivity profile. The two horizontal lines ("whiskers") extending from the central box represent the \pm 1.5 IQR interval. Outliers (points falling out of $\pm 1.5 \mathrm{IQR}$ ) are marked as red crosses. For each error class, the right panel shows the number of observations with height; the red line for error class IV (FA) shows the distribution of outliers with height.

\section{Physical context of retrieval error}

In this section, we focus primarily on diagnosing the potential sources of errors in the retrieval algorithm by studying selected representative TRMM overpasses with substantial discrepancies between 2A25 V7 NSR estimates and raingauge observations, including isolated thunderstorms, mesoscale convective systems, cold fronts, hail events, and snow showers. Figure 9 shows the TRMM overpass in the region of study for each of the selected cases overlaid on the base reflectivity fields from the KMRX and KGSP NWS (National Weather Service) radars, respectively, in Knoxville, TN, and Greer, SC.

\subsection{Local underestimation (II)}

Figure 10a depicts a vertical cross section from the TRMM overpass at 15:08 EDT during a tornado outbreak event (http://earthobservatory.nasa.gov/NaturalHazards/view.

php?id=77308) on 2 March 2012 as the primary squall line was moving over the region (Fig. 9a). After applying the ground-clutter correction, the near-surface rain rate of $4.5 \mathrm{~mm} \mathrm{~h}^{-1}$ at the location marked by the black arrow (viewing angle $7.6^{\circ}$ ) is estimated at $2.25 \mathrm{~km}$ altitude. The co-located raingauge (RG104, Fig. 1) is placed at a much lower elevation $(\sim 1.6 \mathrm{~km})$ and records very heavy rainfall intensity $\left(60 \mathrm{~mm} \mathrm{~h}^{-1}\right)$. In the presence of low-level fog and 

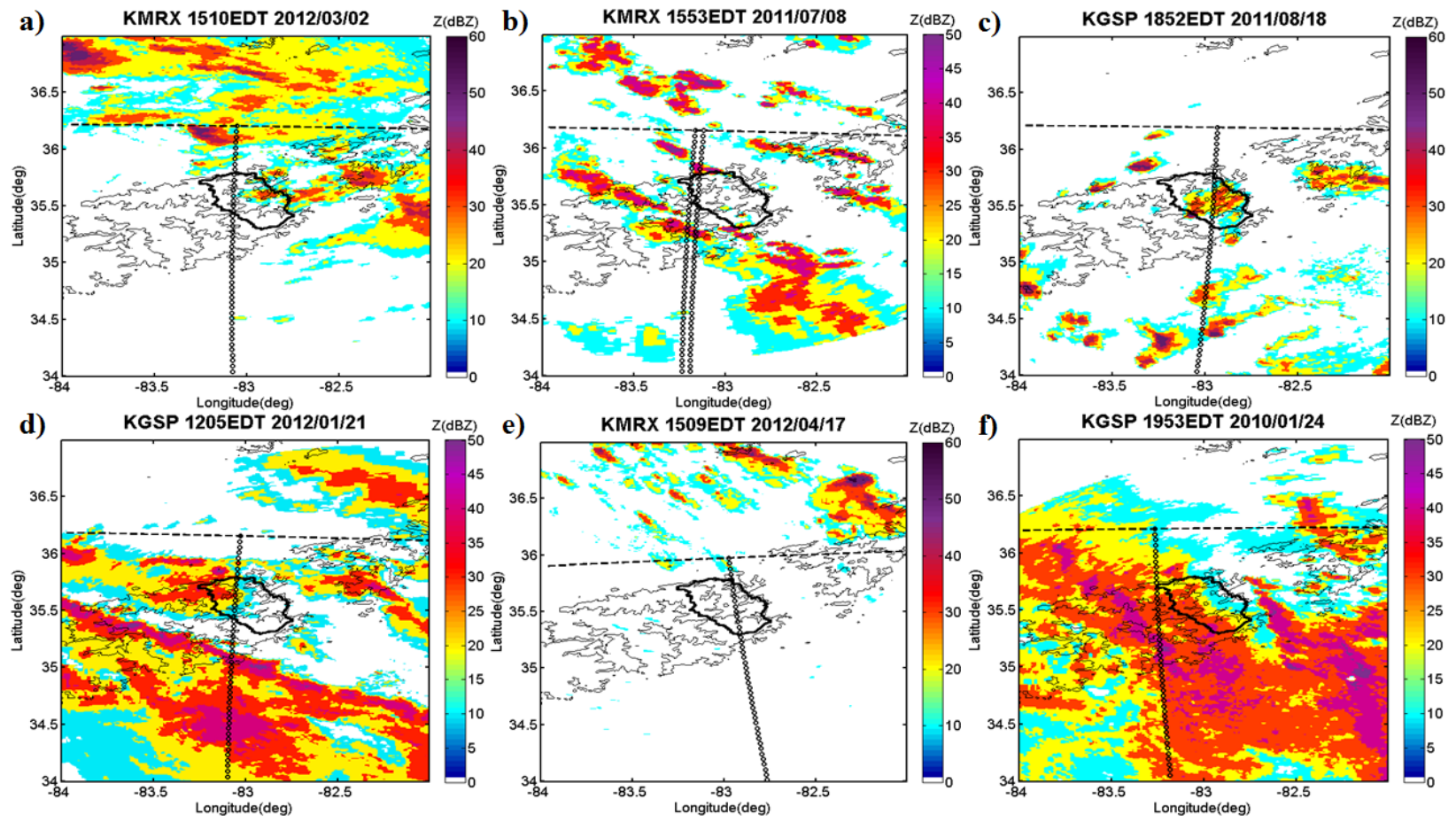

Figure 9. Base reflectivity composites from KMRX (Knoxville, TN) and KGSP (Greer, SC) National Weather Service radars corresponding to the overpass times shown in Figs. 10-12 below. The lines of black circles show the overpass tracks corresponding to the cross sections in Figs. 10-12. The dashed line delimits the northern boundary of the TRMM PR swath over the southern Appalachians, and the $1000 \mathrm{~m}$ terrain elevation contour line and the outline of the study region (the Pigeon River basin) are marked in solid black for reference.

orographic clouds, this difference in elevation $(\sim 650 \mathrm{~m})$ is sufficient to explain the 1 order of magnitude difference in rainfall intensities by seeder-feeder enhanced coalescence (Wilson and Barros, 2014). The PR reflectivity profile extends up to $8 \mathrm{~km}$ in altitude and there is no indication of bright band or large ice-scattering aloft; nevertheless, this pixel is classified as "probably stratiform" (rain type: 120) based on the $\mathrm{H}$ method because of the weak echo. In addition to the ground-clutter filter that eliminates a significant fraction of the measured reflectivity profile at lower levels, the incorrect classification of shallow convection as probably stratiform is also due in part to the effect of spatial averaging over the PR's relatively coarse horizontal resolution, a smoothing effect that is amplified at off-nadir viewing angles. Similar results were reported by Heymsfield et al. (2000), who found that convective precipitation often falls from cells smaller than the PR footprint and its average reflectivity tends to be underestimated due to the NUBF effects, consequently leading to the rain-type classification being artificially biased toward the stratiform type. Nevertheless, an examination of the TRMM reflectivity cross section in Fig. 10a as well as PR $4 \mathrm{~km}$ reflectivity fields (not shown here) clearly reveals the substantial advantage of the satellite-based radar in mountainous regions, where the terrain blocks the monitoring effectiveness of the ground radars (see Fig. 9a).
Figure 10b and c display the vertical cross section of reflectivity and rain rate of two adjacent scans on 8 July 2011, 15:51 EDT, associated with the presence of small bands and clusters of severe summer thunderstorms in the region of interest at the time of overpass (Fig. 9b). Two selected pixels (denoted as pixel 1 on one scan and pixel 2 on the other) observed at $\mathrm{a} \sim 12.1^{\circ}$ angle among those corresponding to the high altitude outliers (red + signs) in Fig. 8c (II) are highlighted here. Note the steep increase in profile reflectivity at altitudes above $4 \mathrm{~km}$ followed by a decrease with height that indicates the existence of a bright band; along with high low-level reflectivities, the vertical structure of reflectivity suggests that over the western slopes of the Appalachians high precipitation rates were produced by a stratiform system with embedded convection. Although gauges RG303 $\left(40 \mathrm{~mm} \mathrm{~h}^{-1}\right)$ and RG311 $\left(60 \mathrm{~mm} \mathrm{~h}^{-1}\right)$ are very close together (Fig. 1), RG303 is located at a higher elevation $(\sim 1.5 \mathrm{~km})$ on the wall of a valley running nearly perpendicular to the western ridge of the southern Appalachians, whereas RG311 is at lower elevation $(\sim 1.25 \mathrm{~km})$ in the valley proper. The TRMM near-surface estimate for both scans is between 22 and $25 \mathrm{~mm} \mathrm{~h}^{-1}$. The effect of the ground-clutter correction is evident in Fig. 10b and c. In addition, note the relative location of the gauges at the boundary between two columns, one with low to moderate reflectivity and one with very high reflectivity in Fig. 10b and c. Because the clusters of shallow 
(a)
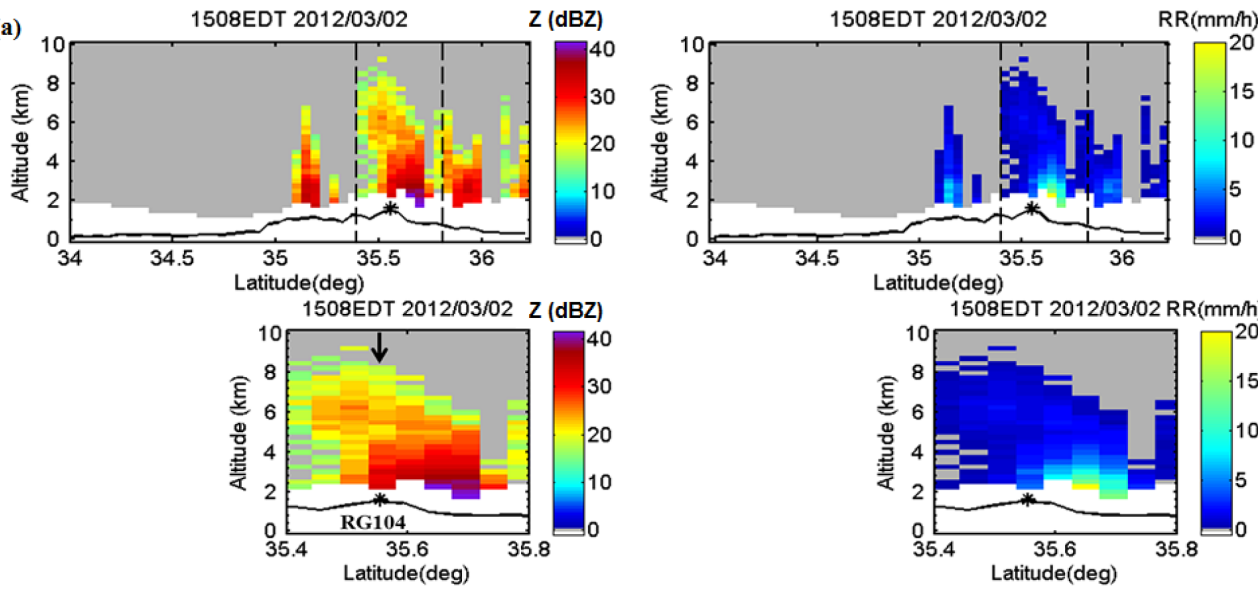

(b)

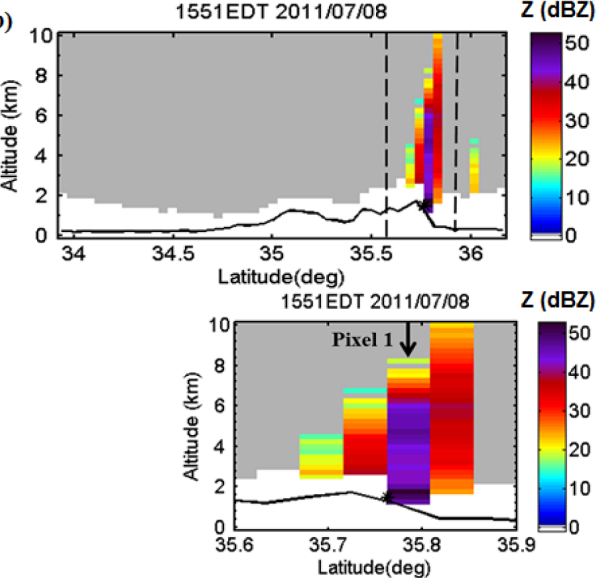

(c)

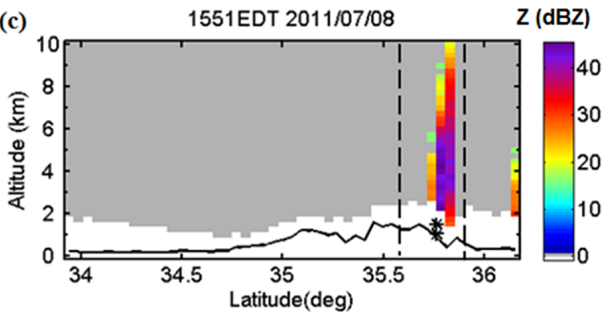

1551EDT 2011/07/08 Z (dBZ)

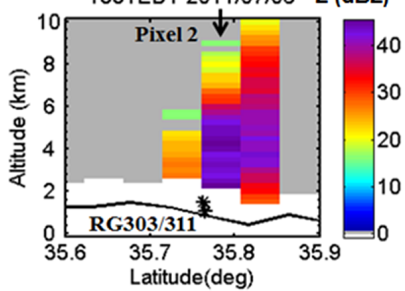

(dBZ)

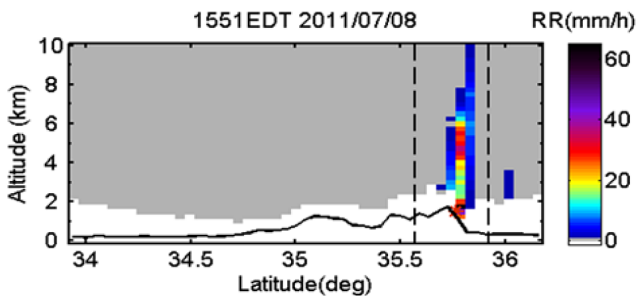

1551EDT 2011/07/08RR(mm/h)
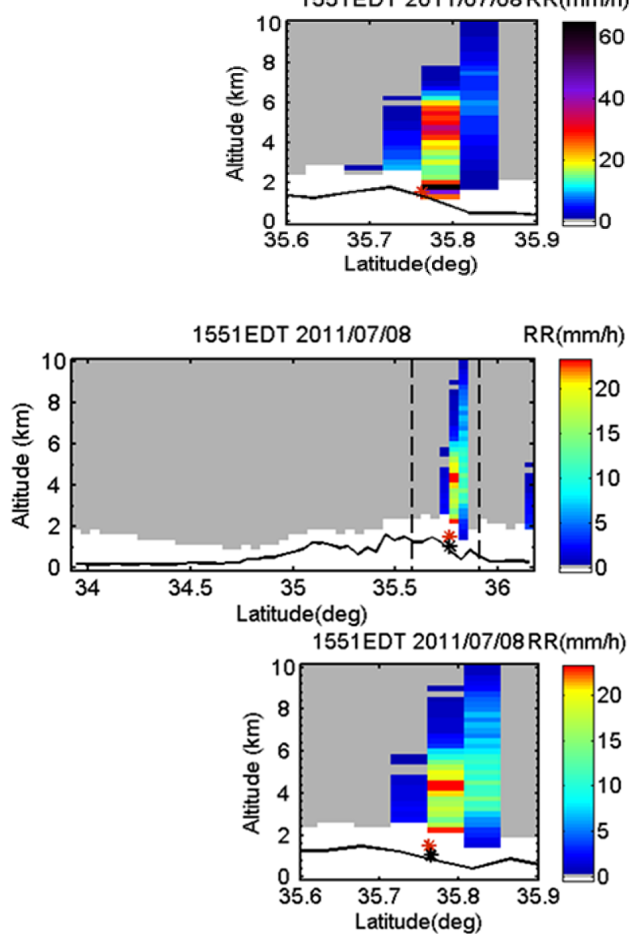

Figure 10. Cross section of reflectivity $(Z)$ and rain rate estimates (RR) from TRMM 2A25 for three underestimation cases: (a) 15:08 EDT on 2 March 2012; and for two different cross sections at 15:51 EDT on 8 July 2011 (b, c). The top row shows the overpass cross section. The bottom row shows the cross section between the two dashed vertical lines in the top rows. Asterisks denote the position of the raingauges as marked, and the color in the right panel is consistent with the measured rain rate. The black arrow identifies the PR profile used to make the error determination. Ground-clutter flags are shown in white. The black continuous line represents the topography. 
embedded convection are very small, averaging significantly reduces the TRMM estimated rainfall and reduces spatial variability. Therefore, TRMM appears to underestimate rainfall from the isolated small-scale summer convective cells, consistent with previous studies demonstrating the underestimation of convection over land by the TRMM PR algorithm (Iguchi et al., 2009; Rasmussen et al., 2013). Among the two raingauge observations in pixel 2, more intense rainfall is observed in the nearby valley (RG311) than on the ridge (RG303), and the PR reflectivity in the valley is much higher than surrounding ridges. Despite horizontal separation in addition to the elevation difference, the low-level enhancement of rainfall at RG311 compared to RG303 is consistent with the increased depth of the precipitation column and ,thus, enhanced raindrop growth by coalescence (Prat and Barros, 2010b; Wilson and Barros, 2014). In such circumstances, orographic rainfall does not increase with elevation as in the canonical model. This event highlights detectability challenges over mountainous regions at coarse horizontal scales (e.g., high spatial variability due to the inability to resolve the complexity of the physics of orographic enhancement). The effective resolution deformation at far-range viewing angles may further contribute to the large underestimation.

\subsection{Local overestimation (III)}

At the time of the TRMM overpass on 18 August 2011, 18:53 EDT, there were small convective clusters and isolated thunderstorms scattered across the region (Fig. 9c). The KMRX radar located in Knoxville, TN, shows no activity over the Appalachians, but the KGSP radar located in Greer, SC, does show activity over the eastern ridges, which is consistent with the shallow isolated cells detected by the TRMM PR shown in Fig. 11a. Classified as "certainly convective" (the reflectivity profiles show no signal of ice scatter aloft), the retrieved near-surface rain rate overestimates the observed precipitation at RG005 $\left(\sim 1.52 \mathrm{~km} ; 12 \mathrm{~mm} \mathrm{~h}^{-1}\right)$ and RG008 $\left(\sim 1.74 \mathrm{~km} ; 18 \mathrm{~mm} \mathrm{~h}^{-1}\right)$ by nearly $60 \%$ on average (viewing angle is $5.2^{\circ}$ ). Interestingly, despite very different vertical structures including the bright band effects for the UND (II) case on 8 July 2011 discussed in Sect. 4.1, the near-surface precipitation estimates derived from TRMM for both cases are about the same $\left(\sim 24 \mathrm{~mm} \mathrm{~h}^{-1}\right)$. However, the OVR(III) problem could be related to the relative position of the two gauges at the edge of the isolated convective cluster (Fig. 9c) as the satellite moves over the orography, in which case NUBF artifacts should lead to overestimation of reflectivity over the gauges outside of the convective cluster. Indeed, the TRMM PR reflectivity between 2 and $4 \mathrm{~km}$ is in the $40-50 \mathrm{dBZ}$ range, whereas the base reflectivity from KGSP at gauge locations is in the $20-30 \mathrm{dBZ}$ range.

Two other relevant OVR (III) cases coincided with the passage of a cold front with a leading pre-frontal convection line in the piedmont on 21 January 2012 that was captured by the TRMM overpass at 12:05 EDT (Fig. 9d), and a pattern of disorganized thunderstorm activity ahead of the propagation of a westerly convective system on 17 April 2012 with overpass at 15:09 EDT (Fig. 9e). The winter system produced major winter snow and ice precipitation from western North Carolina to New York State. In the reflectivity cross section (Fig. 11b), the vertical profiles exhibit a sharp decrease of about $16 \mathrm{dBZ}$ in reflectivity between 2 and $3 \mathrm{~km}$. The TRMM PR rain rate at $\sim 2 \mathrm{~km}$ and the value observed at RG109 in the inner mountain region $(\sim 1.5 \mathrm{~km}$, Fig. 1$)$ are 26.3 and $10.8 \mathrm{~mm} \mathrm{~h}^{-1}$, respectively, resulting in an overestimation of $140 \%$. However, raingauge measurements are expected to exhibit significant errors ( $\sim$ up to $60 \%$ ) for frozen precipitation and even higher for snow in the presence of strong winds. Since this event produced significant snow accumulation and frozen rain, error attribution is an ambiguous proposition.

Both ground-based radars (KMRX, KGSP) miss the deep, isolated convective activity in the mountains that is detected by the TRMM PR (Fig. 11c). The vertical profiles for pixels 1 and 2 over the locations of RG001 and RG010 on the eastern slopes of the Appalachians show large reflectivity (> $30 \mathrm{dBZ}$ ) up to around $6-7 \mathrm{~km}$, suggesting the presence of ice/hail aloft. Records held by the State Climate Office of North Carolina (http://www.nc-climate.ncsu.edu/lsrdb/index.php) reveal multiple reports of intense hail over large areas in the southern Appalachian Mountains at the time. However, raingauge records indicate only 1.2 and $9 \mathrm{~mm} \mathrm{~h}^{-1}$ compared to 25.8 and $36.5 \mathrm{~mm} \mathrm{~h}^{-1}$ from TRMM estimates for pixel 2 (RG001) and pixel 1 (RG010), respectively. Again, this reflects the deficiency of tipping-bucket gauges to capture frozen precipitation, and hail in particular. Conditions in the two pixels are classified as "certainly convective" because of the high horizontal reflectivity gradients. The TRMM PR demonstrates good capability to detect this hail-producing storm.

\subsection{Local false alarms (IV)}

FA (IV) errors can result from NUBF effects for certain viewing angles, terrain and weather configurations due to coarse resolution leading to spatial deformation in reflectivity similar to the problems leading to overestimation in the $\mathrm{Au}-$ gust 2011 case (Fig. 11a) discussed above. Such errors could result from non-precipitating ice clouds or from light snowfall under windy conditions that is missed by the raingauges. Indeed, blizzard conditions were present for the TRMM overpass of 24 January 2010, 19:54 EDT (Fig. 9f). Note the extremely large reflectivity values in the lowest levels in the cross section on the western ridges of the Appalachians displayed in Fig. 12. The vertical profiles exhibit large increments of reflectivity $(22 \mathrm{dBZ})$ and rain rate $\left(47 \mathrm{~mm} \mathrm{~h}^{-1}\right)$ below $4 \mathrm{~km}$. The pixel identified by the black arrow is classified as "certainly convective" and the retrieved near-surface rain rate is $\sim 50 \mathrm{~mm} \mathrm{~h}^{-1}$ at $1.75 \mathrm{~km}$ elevation, whereas the nearest raingauge (RG302, at $1.86 \mathrm{~km}$ ) does not register precipi- 

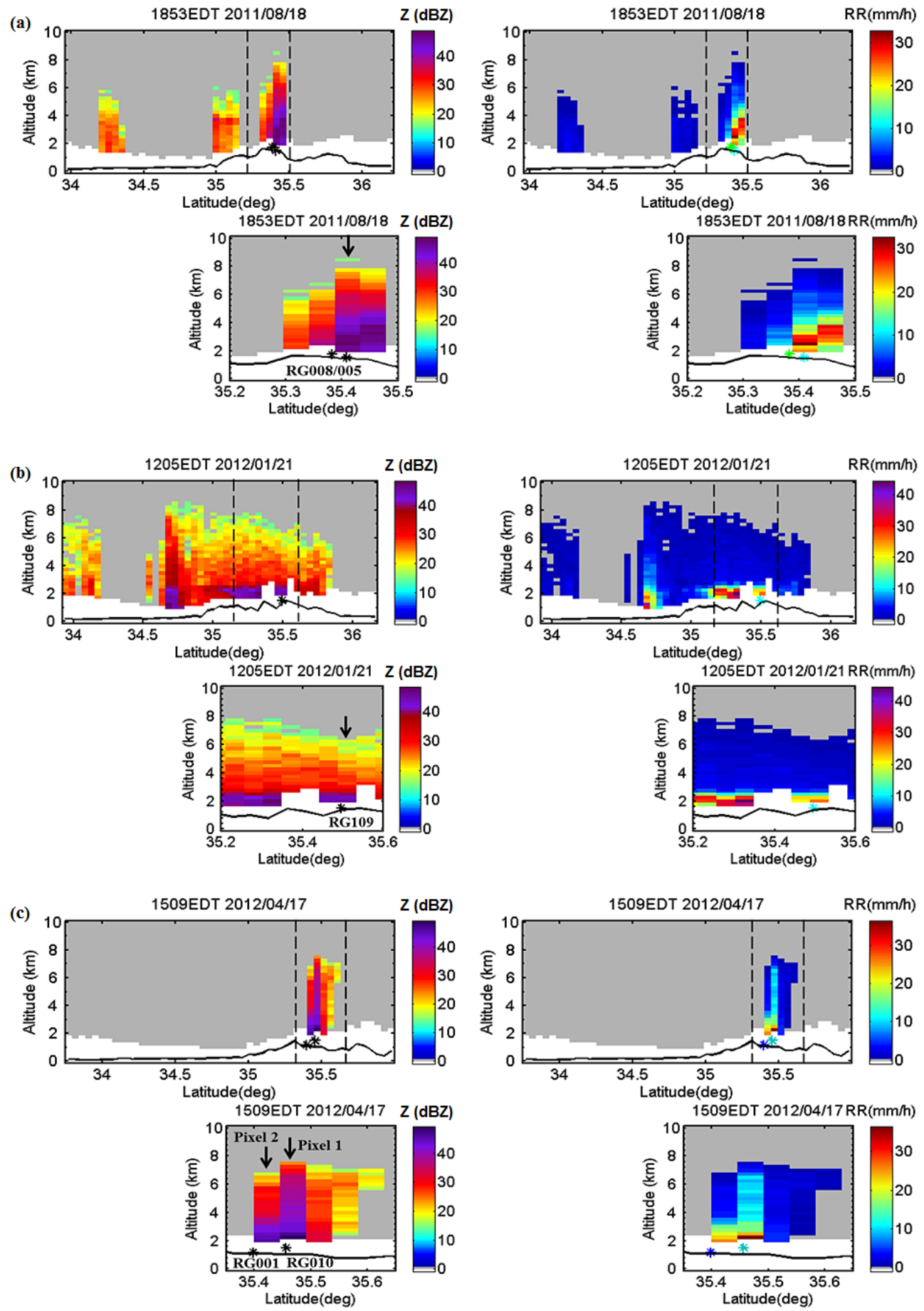

Figure 11. Cross section of reflectivity $(Z)$ and rain rate estimates (RR) from TRMM 2A25 for three overestimation cases, respectively: (a) 18:53 EDT on 18 August 2011; (b) 12:05 EDT on 21 January 2012; and (c) 15:09EDT on 17 April 2012. The top row shows the overpass cross section. The bottom row shows the cross section between the two dashed vertical lines in the top row plots. Asterisks denote the position of the raingauges as marked, and the color in the right panel is consistent with the measured rain rate. The black arrow identifies the PR profile corresponding to the $2 \mathrm{~A} 25$ used to make the error determination. Ground-clutter flags are shown in white. The black continuous line represents the topography. 

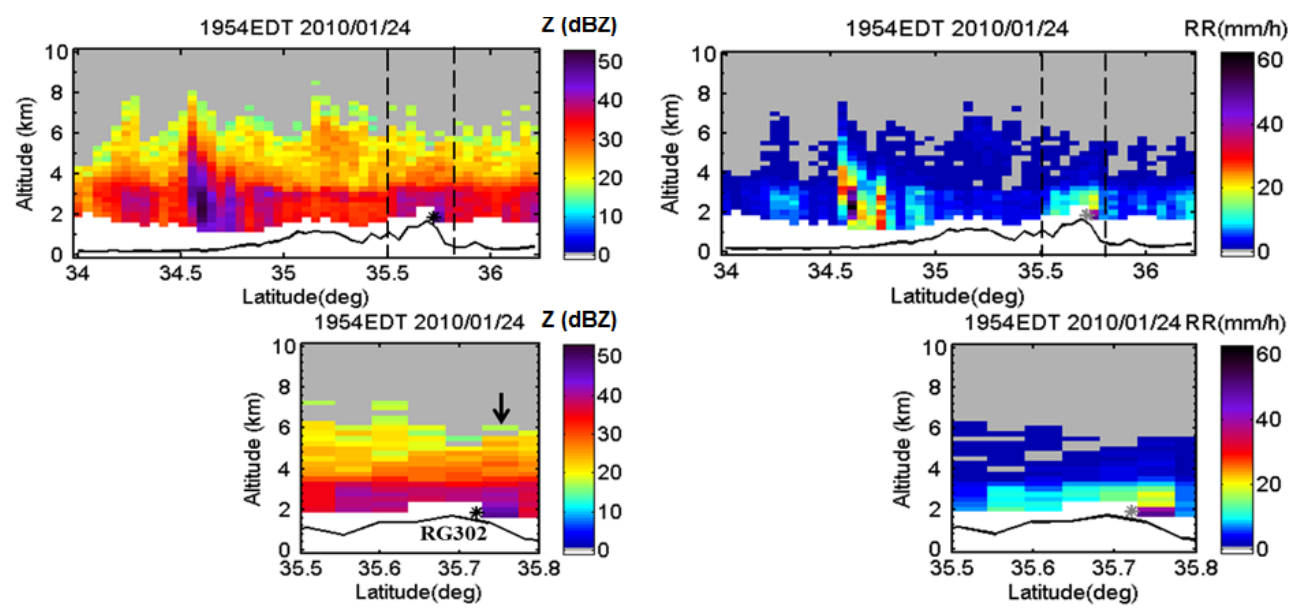

Figure 12. Cross section of reflectivity $(Z)$ and rain rate estimates (RR) from TRMM 2 A25 for a selected case of incorrect false alarm determination at 19:54 EDT on 24 January 2010. The top row shows an overpass cross section. The bottom row shows the cross section between the two dashed vertical lines in the top row plots. Asterisks denote the position of RG302, and the color in the right panel is consistent with the measured rain rate. The black arrow identifies the PR profile used to make the error determination. Ground-clutter flags are shown in white. The black continuous line represents the topography.

tation. According to winter storm reports from the State Climate Office of North Carolina (http://www.nc-climate.ncsu. edu/climate/winter_wx/database.php), snow showers developed across the mountains on 12 January 2010 , resulting in ice and snow accumulation in the lower valleys. The substantial increase in reflectivity at lower levels in the TRMM PR profiles likely results from frozen precipitation particles in cold clouds and/or the accumulated ice and snow in the valleys detected by TRMM.

\section{Summary and conclusions}

TRMM PR 2A25 QPE products were spatiotemporally matched and compared with ground gauges in the southern Appalachian Mountains over a 5-year period, 2008-2013, which provides a statistically large sample of comparisons performed at PR-pixel resolution. The quantitative comparisons yield favorable agreement of the PR with raingauge observations, with clear advantage over remote ground-based operating radars, but errors can be significant depending on the underlying rainfall regimes.

First, V7 and V6 QPEs were inter-compared in order to assess the impact of retrieval algorithm changes such as reintroducing the NUBF correction, recalibration of the $Z-R$ relationship over land, and attenuation correction of the PR radar signal. Although a small improvement from V6 to V7 was identified at high to moderate rainfall rates, the results do not show significant differences in warm-season precipitation detection skill.

Based on the TRMM rain-type classification, characteristic features in the vertical structure of reflectivity and retrieved rainfall profiles that can be associated with distinct error characteristics under various precipitation regimes were identified. Regardless of error type, a significant fraction of estimation errors occurs when rainfall is classified as "probably stratiform", which is hypothesized to result from the compounded effect of radar sensitivity and NUBF that renders the PR detectability of bright band unreliable for smallscale systems, especially at far-viewing angles. The statistics of FAs are highly sensitive to the measurement threshold of the raingauges (TB tip size) and the phase of precipitation. Nevertheless, the errors exhibit a relatively constant rate of occurrence throughout the year, a strong diurnal cycle with early and mid-afternoon peaks, a large skew of the rain rates toward low values $\left(<5 \mathrm{~mm} \mathrm{~h}^{-1}\right)$, and the highest incidence is in the inner mountain region. This suggests that averaging at the coarse resolution of the PR pixel eliminates the signature of the small-scale complex structure of isolated orographic convection and localized multi-layered clouds and fog that are dominant in the region and, thus, explains the high number of FA counts using the point-to-pixel strategy used here.

MDs show a strong annual cycle occurring predominantly during the cold season and into the spring with very low values in the summer. The diurnal cycle indicates that MDs appear linked to fog and multi-tiered low-level clouds especially in the inner mountain region, which the TRMM PR products fail to detect due to the ground-clutter correction. The high reflectivity sensitivity threshold of the PR can also result in failure to detect weak echoes, thus, missing detection of light rainfall. Ground-clutter contamination is not a problem inherent to the TRMM PR alone, but it is rather a general challenge for all space-based radars such as the DPR (Dual-frequency Precipitation Radar) on the GPM satellite. This work took advantage of multiple sources of concurrent and co-located observations to investigate in detail the con- 
ditions associated with different types of error, which should be helpful in identifying opportunities for improving retrieval algorithms in regions of complex terrain, despite the challenges, particularly at the current spatial resolution. Specifically in the case of surface contamination, special precaution should be taken when strong echoes are observed near the surface, an indication of surface clutter artifacts that should be excluded from rain analysis. Because of the importance of persistent low-level clouds and light rainfall in mountainous regions, generally, there is a critical need to develop retrieval strategies that can capture the vertical structure of lowlevel reflectivity and the associated rainfall in complex terrain. This can be accomplished for instance by integrating operational satellite retrieval algorithms with simple physical models targeting local processes (e.g., Prat and Barros, 2009; Wilson and Barros, 2014).

Albeit of low frequency, heavy precipitating events have a significant hydrologic impact leading to extreme floods and landslides in the region. Six representative case studies with substantial discrepancies between TRMM and gauge references provide insight into the characteristics of PR rainfall retrieval errors that need to be taken into consideration for applications in complex terrain. The results show that TRMM tends to underestimate small-scale winter storms and embedded convection in the summer, which can be attributed to the averaging effects of NUBF at TRMM PR coarse horizontal resolution as well as misclassification of convective systems as stratiform, especially at large incidence angles. Precipitation from warm season convective systems smaller than the PR footprint is either underestimated or overestimated depending on the size of the system footprint and the depth of active convection. In particular, TRMM tends to underestimate rainfall from embedded convection, and overestimates rainfall from isolated small-scale shallow convection when and where it is detected. Cold-season mixed-phase precipitation (e.g., hail, and ice falling through melting layers) is associated with a strong scattering signal from ice crystals and can be misclassified as "certain convective". Mixedphase precipitation cannot be estimated by the convective $Z-$ $R$ (reflectivity-rainfall) relationship in the algorithm, leading to the severe overestimation or false alarm errors in the winter and spring seasons.

Diagnostic analysis focusing on the characterization of the physical basis of the QPE error provides a framework for error source attribution and, generally, subsequent correction or mitigation of satellite retrievals and can be applied elsewhere. Based on the results presented here, the observing strategy devised for IPHEx placed strong emphasis on documenting the spatial and temporal heterogeneity of rainfall microphysics conditional on time of day, prevalent hydrometeorological regime, and topographic and physiographic context (Barros et al., 2014). Special emphasis was placed on the vertical structure of precipitation in the lower troposphere. Analysis of IPHEx results is ongoing.
Acknowledgements. This research was funded in part by NASA grant NNX13AH39G to the third author A. P. Barros.

Edited by: P. Molnar

\section{References}

Amitai, E., Llort, X., and Sempere-Torres, D.: Comparison of TRMM Radar Rainfall Estimates with NOAA NextGeneration QPE, J. Meteorol. Soc. Jpn., 87A, 109-118, doi:10.2151/jmsj.87A.109, 2009.

Amitai, E., Unkrich, C. L., Goodrich, D. C., Habib, E., and Thill, B.: Assessing Satellite-Based Rainfall Estimates in Semiarid Watersheds Using the USDA-ARS Walnut Gulch Gauge Network and TRMM PR, J. Hydrometeorol., 13, 1579-1588, doi:10.1175/jhm-d-12-016.1, 2012.

Barros, A. P.: Orographic precipitation, freshwater resources, and climate vulnerabilities in mountainous regions, in: Climate Vulnerability: Understanding and Addressing Threats to Essential Resources, Elsevier Inc., Academic Press, Waltham, Massachusetts, 57-78, 2013.

Barros, A. P. and Tao, K.: A Space-Filling Algorithm to Extrapolate Narrow-Swath Instantaneous TRMM Microwave Rain-Rate Estimates Using Thermal IR Imagery, J. Atmos. Ocean. Tech., 25, 1901-1920, doi:10.1175/2008jtecha1019.1, 2008.

Barros, A. P., Joshi, M., Putkonen, J., and Burbank, D. W.: A study of the 1999 monsoon rainfall in a mountainous region in central Nepal using TRMM products and rain gauge observations, Geophys. Res. Lett., 27, 3683-3686, doi:10.1029/2000g1011827, 2000.

Barros, A. P., Petersen, W., Schwaller, M., Cifelli, R., Mahoney, K., Peters-Liddard, C., Shepherd, M., Nesbitt, S., Wolff, D., Heymsfield, G., Starr, D., Anognostou, E., Gourley, J. J., Kim, E., Krajewski, W., Lackman, G., Lang, T., Miller, D., Mace, G., Petters, M., Smith, J., Tao, W.-K., Tsay, S.-C., and Zipser, E.: NASA GPM-Ground Validation: Integrated Precipitation and Hydrology Experiment 2014 Science Plan, Duke University, Durham, NC, 64 pp., doi:10.7924/G8CC0XMR, 2014.

Bindlish, R. and Barros., A. P.: Multifrequency Soil Moisture Inversion from SAR Measurements with the Use of IEM, Remote Sens. Environ., 71, 67-88, doi:10.1016/S0034-4257(99)000656, 2000.

Chen, Y., Ebert, E. E., Walsh, K. J. E., and Davidson, N. E.: Evaluation of TRMM 3B42 precipitation estimates of tropical cyclone rainfall using PACRAIN data, J. Geophys. Res.-Atmos., 118, 2184-2196, doi:10.1002/jgrd.50250, 2013.

Durden, S. L., Haddad, Z. S., Kitiyakara, A., and Li, F. K.: Effects of nonuniform beam filling on rainfall retrieval for the TRMM precipitation radar, J. Atmos. Ocean. Tech., 15, 635-646, 1998.

Fisher, B. L.: Climatological Validation of TRMM TMI and PR Monthly Rain Products over Oklahoma, J. Appl. Meteorol., 43, 519-535, doi:10.1175/15200450(2004)043<0519:CVOTTA>2.0.CO;2, 2004.

Habib, E. and Krajewski, W. F.: Uncertainty analysis of the TRMM ground-validation radar-rainfall products: Application to the TEFLUN-B field campaign, J. Appl. Meteorol., 41.5, 558-572, 2002. 
Heymsfield, G. M., Geerts, B., and Tian, L.: TRMM Precipitation Radar Reflectivity Profiles as Compared with High-Resolution Airborne and Ground-Based Radar Measurements, J. Appl. Meteorol., 39, 2080-2102, doi:10.1175/15200450(2001)040<2080:TPRRPA>2.0.CO;2, 2000.

Iguchi, T., Kozu, T., Meneghini, R., Awaka, J., and Okamoto, K.: Rain-Profiling Algorithm for the TRMM Precipitation Radar, J. Appl. Meteorol., 39, 2038-2052, doi:10.1175/15200450(2001)040<2038:RPAFTT>2.0.CO;2, 2000.

Iguchi, T., Kozu, T., Kwiatkowski, J., Meneghini, R., Awaka, J., and Okamoto, K. i.: Uncertainties in the Rain Profiling Algorithm for the TRMM Precipitation Radar, J. Meteorol. Soc. Jpn., 87A, 130, doi:10.2151/jmsj.87A.1, 2009.

Kirstetter, P.-E., Hong, Y., Gourley, J. J., Schwaller, M., Petersen, W., and Zhang, J.: Comparison of TRMM 2A25 Products, Version 6 and Version 7, with NOAA/NSSL Ground RadarBased National Mosaic QPE, J. Hydrometeorol., 14, 661-669, doi:10.1175/jhm-d-12-030.1, 2013.

Kozu, T. and Iguchi, T.: Nonuniform Beamfilling Correction for Spaceborne Radar Rainfall Measurement: Implications from TOGA COARE Radar Data Analysis, J. Atmos. Ocean. Technol., 16, 1722-1735, doi:10.1175/15200426(1999)016<1722:NBCFSR>2.0.CO;2, 1999.

Kozu, T., Kawanishi, T., Kuroiwa, H., Kojima, M., Oikawa, K., Kumagai, H., Okamoto, K., Okumura, M., Nakatsuka, H., and Nishikawa, K.: Development of precipitation radar onboard the Tropical Rainfall Measuring Mission (TRMM) satellite, IEEE Trans., Geosci. Remote Sens., 39, 102-116, doi:10.1109/36.898669, 2001.

Lang, T. J. and Barros, A. P.: An investigation of the onsets of the 1999 and 2000 monsoons in central Nepal, Mon. Weather Rev., 130, 1299-1316, 2002.

Liao, L. and Meneghini, R.: Validation of TRMM Precipitation Radar through Comparison of Its Multiyear Measurements with Ground-Based Radar, J. Appl. Meteorol. Clim., 48, 804-817, doi:10.1175/2008jamc1974.1, 2009.

Meneghini, R., Iguchi, T., Kozu, T., Liao, L., Okamoto, K., Jones, J. A., and Kwiatkowski, J.: Use of the Surface Reference Technique for Path Attenuation Estimates from the TRMM Precipitation Radar, J. Appl. Meteorol., 39, 2053-2070, doi:10.1175/15200450(2001)040<2053:UOTSRT>2.0.CO;2, 2000.

Nakamura, K.: Biases of rain retrieval algorithms for spaceborne radar caused by nonuniformity of rain, J. Atmos. Ocean. Tech., 8, 363-373, 1991.

Nesbitt, S. W., Zipser, E. J., and Cecil, D. J.: A Census of Precipitation Features in the Tropics Using TRMM: Radar, Ice Scattering, and Lightning Observations, J. Clim., 13, 4087-4106, doi:10.1175/1520-0442(2000)013<4087:ACOPFI> 2.0.CO;2, 2000.

Okamoto, K., Meneghini, R., Iguchi, T., Awaka, J., and Shimizu, S.: TRMM PR algorithms version 6 status and plans for version 7, in: Asia-Pacific Remote Sensing of the Atmosphere and Clouds II, November 17, Noumea, New Caledonia, edited by: Stephens, G. L. and Nakajima, T. Y., Proc. SPIE 7152, 715208, doi:10.1117/12.804932, 2008.

Porcù, F., Milani, L., and Petracca, M.: On the uncertainties in validating satellite instantaneous rainfall estimates with raingauge operational network, Atmos. Res., 144, 73-81, doi:10.1016/j.atmosres.2013.12.007, 2014.
Prasetia, R., As-syakur, A. R., and Osawa, T.: Validation of TRMM Precipitation Radar satellite data over Indonesian region, Theor. Appl. Climatol., 112, 575-587, doi:10.1007/s00704-012-0756-1, 2012.

Prat, O. P. and Barros, A. P.: Exploring the Transient Behavior of $Z-R$ relationships: Implications for Radar Rainfall Estimation, J. Appl. Meteorol. Clim., 48, 2127-2143, doi:10.1175/2009JAMC2165.1, 2009.

Prat, O. P. and Barros, A. P.: Assessing satellite-based precipitation estimates in the Southern Appalachian mountains using rain gauges and TRMM PR, Adv. Geosci., 25, 143-153, doi:10.5194/adgeo-25-143-2010, 2010a.

Prat, O. P. and Barros, A. P.: Ground observations to characterize the spatial gradients and vertical structure of orographic precipitation - Experiments in the inner region of the Great Smoky Mountains, J. Hydrol., 391, 141-156, doi:10.1016/j.jhydrol.2010.07.013, 2010b.

Rasmussen, K. L., Choi, S. L., Zuluaga, M. D., and Houze, R. A.: TRMM precipitation bias in extreme storms in South America, Geophys. Res. Lett., 40, 3457-3461, doi:10.1002/grl.50651, 2013.

Seto, S., Iguchi, T., and Meneghini, R.: Comparison of TRMM PR V6 and V7 Focusing Heavy Rainfall, Geoscience and Remote Sensing Symposium (IGARSS), 2011 IEEE International, Vancouver, Canada, 24-29 July, 2582-2585, 2011.

Tao, K., and Barros, A. P.: Using Fractal Downscaling of Satellite Precipitation Products for Hydrometeorological Applications, J. Atmos. Ocean. Tech., 27, 409-427, doi:10.1175/2009jtecha1219.1, 2010.

Tao, J. and Barros, A. P.: Prospects for flash flood forecasting in mountainous regions - An investigation of Tropical Storm Fay in the Southern Appalachians, J. Hydrol., 506, 69-89, doi:10.1016/j.jhydrol.2013.02.052, 2013.

Tao, J. and Barros, A. P.: Coupled prediction of flood response and debris flow initiation during warm- and cold-season events in the Southern Appalachians, USA, Hydrol. Earth Syst. Sci., 18, 367388, doi:10.5194/hess-18-367-2014, 2014.

Viviroli, D., Archer, D. R., Buytaert, W., Fowler, H. J., Greenwood, G. B., Hamlet, A. F., Huang, Y., Koboltschnig, G., Litaor, M. I., López-Moreno, J. I., Lorentz, S., Schädler, B., Schreier, H., Schwaiger, K., Vuille, M., and Woods, R.: Climate change and mountain water resources: overview and recommendations for research, management and policy, Hydrol. Earth Syst. Sci., 15, 471-504, doi:10.5194/hess-15-471-2011, 2011.

Wang, J. and Wolff, D. B.: Evaluation of TRMM Ground-Validation Radar-Rain Errors Using Rain Gauge Measurements, J. Appl. Meteorol. Clim., 49, 310-324, doi:10.1175/2009jamc2264.1, 2010.

Wilson, A. M. and Barros, A. P.: An Investigation of Warm Rainfall Microphysics in the Southern Appalachians: Orographic Enhancement via Low-Level Seeder-Feeder Interactions, J. Atmos. Sci., 71, 1783-1805, doi:10.1175/jas-d-13-0228.1, 2014.

Wolff, D. B. and Fisher, B. L.: Comparisons of Instantaneous TRMM Ground Validation and Satellite Rain-Rate Estimates at Different Spatial Scales, J. Appl. Meteorol. Clim., 47, 22152237, doi:10.1175/2008jamc1875.1, 2008.

Yang, S. and Nesbitt, S. W.: Statistical properties of precipitation as observed by the TRMM precipitation radar, Geophys. Res. Lett., 41, 5636-5643, doi:10.1002/2014g1060683, 2014. 